\title{
La Bolsa de Valores de México durante el porfiriato y la revolución, 1885-1934*
}

\section{The Stock Exchange in Mexico during the Porfiriato and the Revolution, 1885-1934}

\author{
Javier Moreno Lázaro \\ Universidad de Valladolid, España, email:Jmoreno@eco.uva.es
}

\begin{abstract}
Resumen. En este artículo se sostiene que la Bolsa de México sólo contribuyó a la financiación empresarial desde su fundación hasta el inicio de la revolución. Allí encontraron fuentes de financiación empresarios mineros, banqueros e industriales. Pero desde entonces, particularmente desde la aplicación de la doctrina de Carranza en 1916, la Bolsa se convirtió en un mero instrumento financiero del Estado y sirvió entonces casi exclusivamente para la suscripción de deuda. Para demostrar esta hipótesis se presentan series cuantitativas inéditas que miden los efectos de la actividad bursátil en el desarrollo económico del país, al margen de los aspectos específicamente financieros.
\end{abstract}

Palabras clave: Bolsa de México; intervención del Estado; deuda pública; crisis monetaria.

\begin{abstract}
This paper holds that the Mexican Stock Exchange was merely a contribution to business financing from its opening to the beginning of the Revolution. Mining investors, bankers, and industrial found financing sources in it. Since then, particularly since the implementation of the Carranza policy in 1916, the Stock Market became a mere financing tool for the State, serving almost exclusively for the subscription of foreign debt. To prove this hypothesis quantitative unprecedented series are presented measuring the impact of the stock market activity on the country's economical development, apart from the specific financial aspects.
\end{abstract}

Key words: Mexican Stock Exchange; State intervention; public debt; currency crisis.

Fecha de recepción: 14 de diciembre de 2015. Fecha de aceptación: 6 de junio de 2016.

* Este trabajo se realizó con el respaldo financiero del Ministerio de Economía y Competitividad del gobierno de España, contemplado en el proyecto de investigación HAR2013-41121-P.

Am. Lat. Hist. Econ., ene.-abr., 2017, pp. 98-139 | DOI: 10.18232/alhe.v24i1.729 


\section{INTRODUCCIÓN}

$\mathrm{E}$ 1 papel que desempeñó la Bolsa en el crecimiento económico de México, en los primeros años de la globalización, ha sido subestimado por la historiografía estadunidense, a pesar del interés que le confiere la revolución y sus postulados económicos. De hecho América Latina se ha tenido poco en cuenta en la reconstrucción de la historia financiera desde la primera globalización (Dimson, Marsh y Staunton, 2009). No obstante, el agravio con México es mayor. A diferencia de la contribución del sistema bancario a la industrialización del país, de lo sucedido en la Bolsa en los años que van desde la llegada al poder de Porfirio Díaz en 1876, al fin de la revolución, poco sabemos. Su debilitamiento posterior no es excusa, justamente porque ha de ser explicado. Resulta difícil encontrar trabajos que le hayan prestado una mínima atención. Haber (1997) y Maurer (2002) se refieren a ella de soslayo y sin citarla expresamente en sus estudios sobre el mercado de capitales. Sólo Ángel (2002) y Cárdenas y Ángel (2011) le han prestado la atención debida. En suma, contamos con una historia financiera sobre México amputada por la inexplicable omisión de la Bolsa en algunos de los sesudos estudios mencionados, que sus aparatosos contrastes estadísticos no disculpan.

Este trabajo examina el papel atribuido a la Bolsa en el periodo de integración y liberalización de la economía mexicana y el que tuvo tras el abandono de ambos principios, inmediatamente después del inicio de la revolución, para abrazar los de la estatalización y la protección. Fue mucho más eficaz en la financiación empresarial en el primero de los periodos. En 1913 la Bolsa se convirtió en un mero intermediario financiero al servicio del Estado, en lugar de ser un agente que coadyuvase a la industrialización del país tal y como fue concebida en sus orígenes.

Por último, se demuestra que el elevado endeudamiento del sector público causó las recurrentes crisis bursátiles. La insolvencia crónica de México y su deuda externa provocaron turbulencias periódicas en el mercado interno de capitales de extrema virulencia.

En síntesis, el Estado desde el inicio de la revolución entorpeció la labor de la Bolsa por dos medios: el endeudamiento y la intervención. Demostrar esta hipótesis es el objetivo prioritario de este trabajo.

Pero, al mismo tiempo, la intención es dejar por escrito algunas reflexiones de índole metodológica que puedan servir para el desarrollo de la historia bursátil de América Latina, lastrada por los prejuicios acerca de su debilidad formulados por la historiografía estadunidense. Hay una realidad por dar a conocer, la del mercado de bonos y acciones en estas tierras, de la que poco sabemos. Pasar por alto lo sucedido ahí invita a verter interpretaciones sobre el atraso económico de América Latina desde una 
perspectiva financiera forzosamente sesgada. Argüir la ausencia de datos sin tratar de remediar el problema ni permitir que se haga ejercicio analítico alguno, como ha sucedido hasta la fecha, no conduce a ningún sitio.

\section{LA CONSTRUCCIÓN DE LOS ÍNDICES DE COTIZACIONES}

Las mencionadas carencias estadísticas bursátiles en México son mayores que en otros países latinoamericanos. Esto se debe a la pérdida del archivo de la Bolsa y a la carencia de datos oficiales que puedan subsanar su falta. Los primeros índices de cotizaciones de la Bolsa de México fueron publicados por la Sociedad de Naciones en 1937. Sólo desde 1960 la Nacional Financiera elaboró series retrospectivas que se remontan hasta 1933 (Nacional Financiera, 1977, pp. 340-348). El volumen negociado sólo fue cuantificado y divulgado desde 1909. La ausencia de información es aún mayor en lo que se refiere a la renta fija, de valores emitidos tanto por la Hacienda pública como por las empresas, y a la deuda externa. No hay cálculos oficiales disponibles de ninguna de estas variables. En México, pues, a diferencia de otros países americanos, los agentes económicos no dispusieron de indicadores bursátiles comúnmente aceptados y elaborados por la propia Bolsa o las autoridades reguladoras.

Para remediar, en lo posible, este vacío estadístico, se ha construido un índice Laspeyres con una treintena de valores industriales, bancarios y mineros que cotizaron a lo largo de todo el periodo, ponderados con arreglo al volumen de negociación de cada uno de los grupos sectoriales señalados (véanse gráficas 1,2 y 3 , así como los datos anuales en el anexo). Para ello se sigue escrupulosamente la metodología aplicada por la Bolsa Mexicana desde 1978 hasta 2012 en la confección del viejo índice de precios y cotizaciones, sobre cuya fiabilidad no consta mayor crítica por analistas ni académicos.

Se han obtenido sus cotizaciones de la monografía de Alfredo Lagunilla-Iñarritu (1973). El peso atribuido en cada sector, a falta de datos sobre el total de acciones vendidas, corresponde al del capital suscrito y desembolsado. Los precios empleados son los abonados en las operaciones al contado, en billetes, salvo entre 1916 y 1930, en metal. Las acciones (a diferencia de los bonos) por lo común no fueron emitidas con descuentos sobre su valor facial, aunque, en caso contrario, tal eventualidad tampoco influiría en mis cálculos. Para la conversión del índice a términos reales, entre 1888 y 1899, así como entre 1910 y 1920, se ha empleado como deflactor el índice de precios al consumo, en ausencia del deflactor implícito del PIB.

El índice tiene sus limitaciones, habida cuenta de la penuria estadística a la que he tenido que enfrentarme; pero es lo más elaborado que se puede 


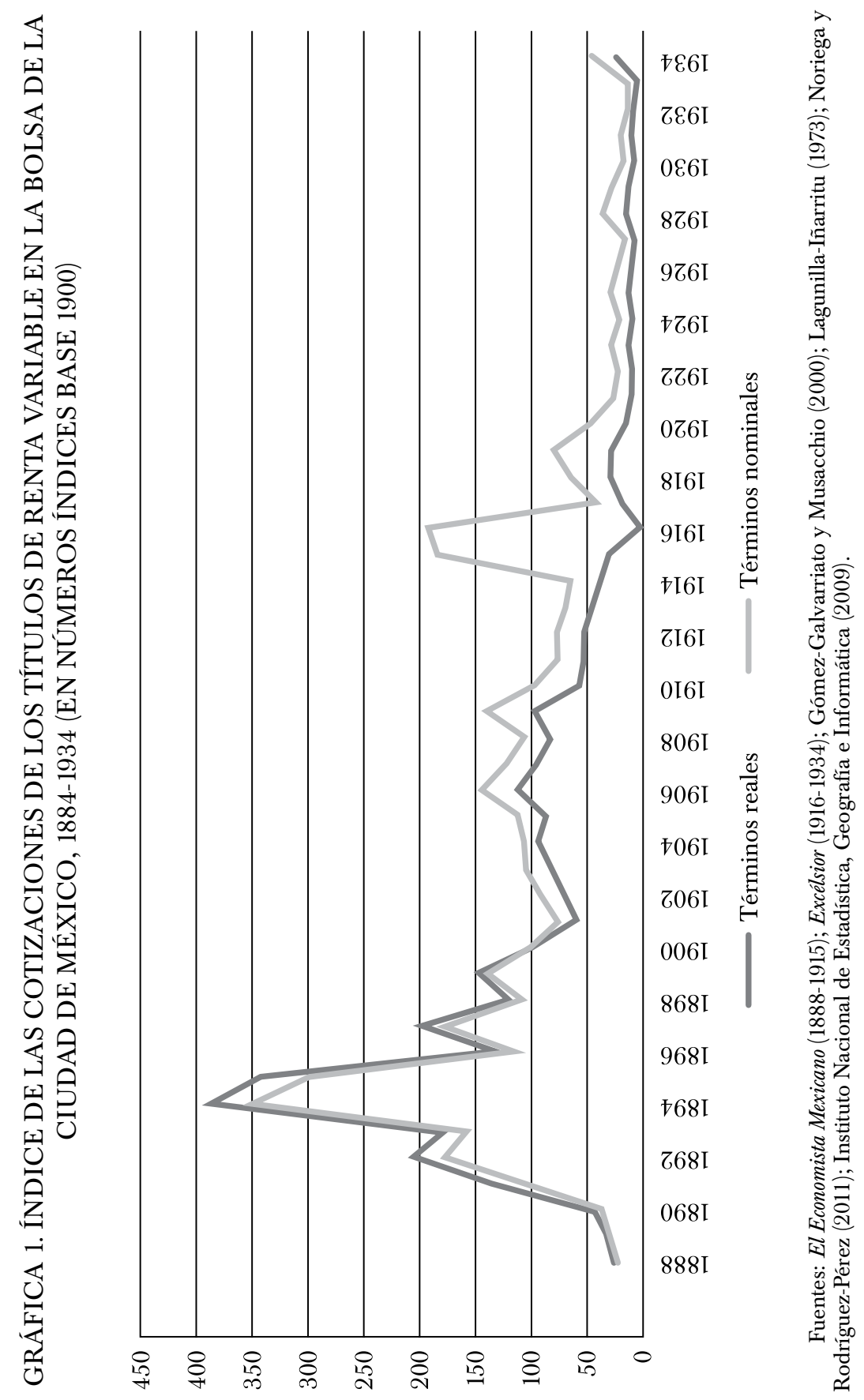




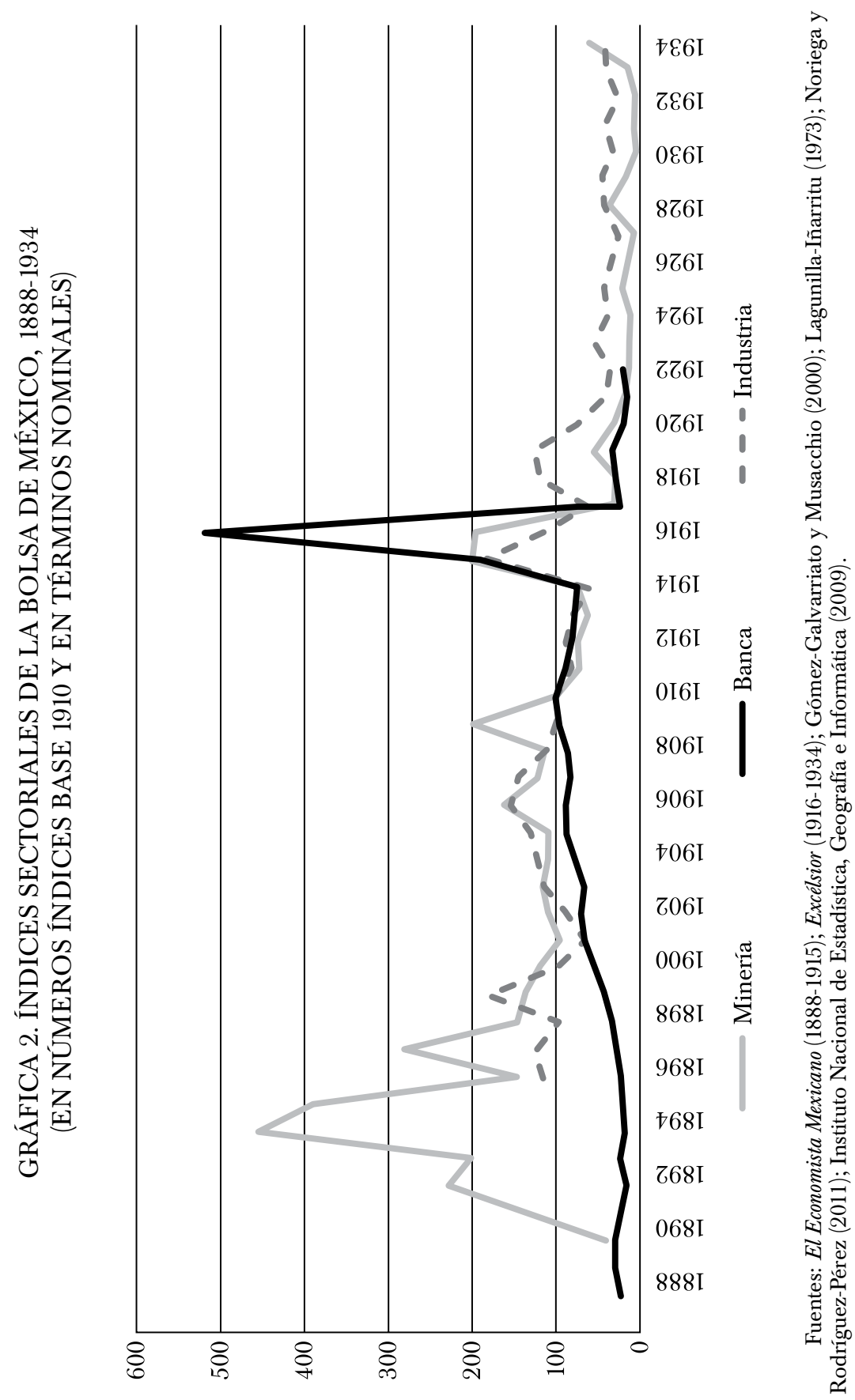




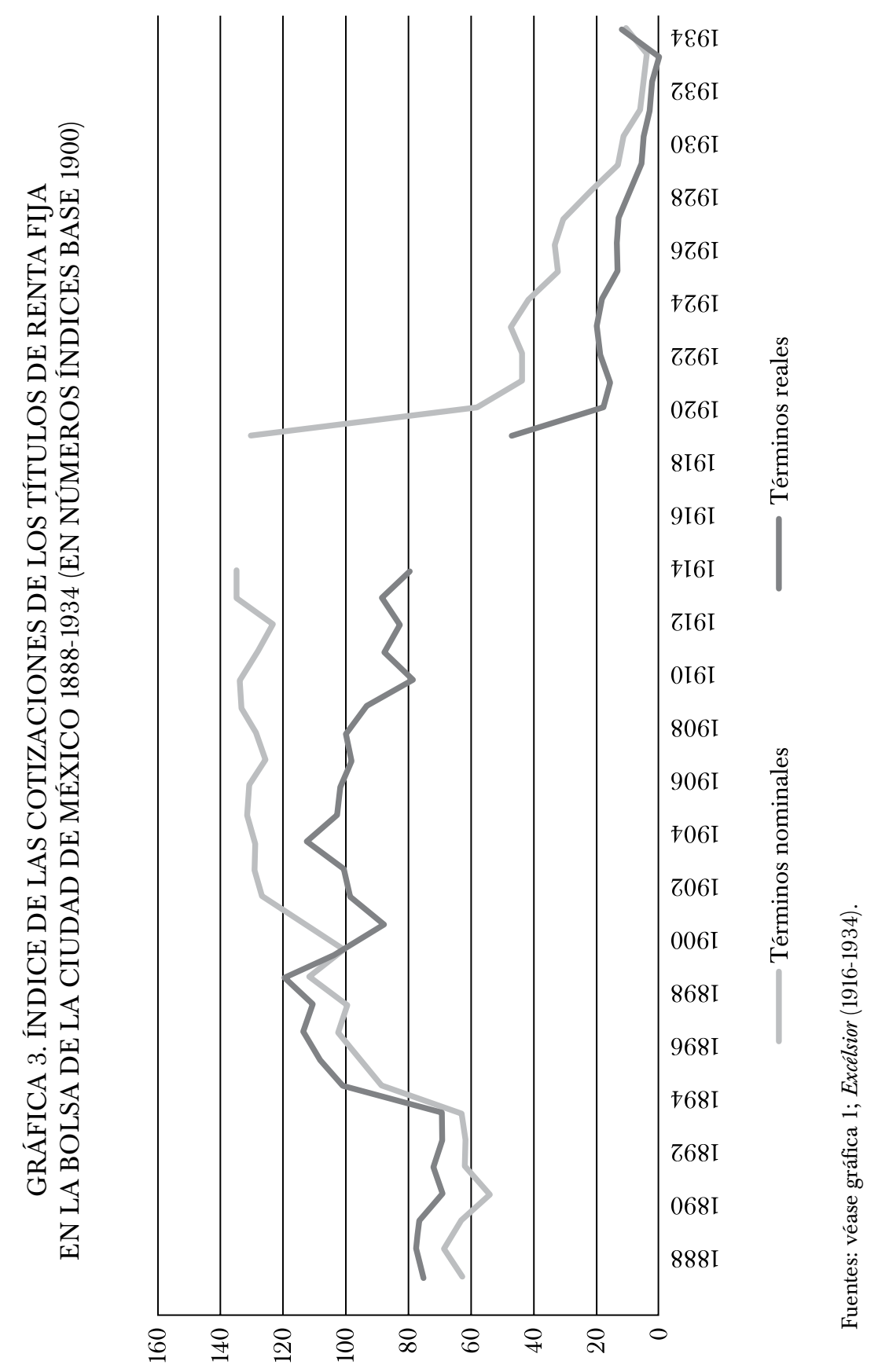


hacer, y lo más importante, el único que se ha realizado hasta la fecha. Dicho en otras palabras, la alternativa consiste en avanzar con una primera serie de cotizaciones más o menos certera o perseverar en la conjetura y en los epítetos.

Es preciso medir, desde luego, tarea inexcusable en la historia financiera. Pero para ello hay que tener en cuenta los datos de que disponemos y lo que podemos hacer con ellos. Hubiese o no archivo, ni en México ni en ningún otro país de América (incluido Estados Unidos), hay forma de elaborar índices sintéticos como los que hoy precisan los inversores que incluyan la rotación de la acción, liquidez, precios de apertura y cierre o porcentajes de acciones flotantes, por citar algunos de los cálculos menos aparatosos. Esto se debe a que simple y llanamente no se elaboraban, dado que los corredores no necesitan de más información que el precio medio alcanzado por esa acción. Todo lo demás, las memorias de las Bolsas, si están disponibles (que no es el caso), informaban sobre el volumen cotizado cuando empezaron a financiarse con aranceles sobre las transacciones. No se puede exigir más de lo que los agentes económicos concernidos reclamaban, de la misma manera que, por poner un ejemplo burdo, no tiene sentido buscar datos oficiales contemporáneos sobre el PIB mexicano antes de 1959. La complejidad de los índices con los que hoy se opera obedece, al margen del propio avance de la estadística como disciplina, a la multiplicación de las alternativas inversoras. Entonces no existían más que tres: acciones, bonos y obligaciones. Con noticias sobre las cotizaciones medias y los dividendos (magnitudes con las que yo opero) bastaba en la toma de decisiones. Los analistas de la época pecaron de pragmatismo y poca visión de futuro, si se me permite la licencia.

El garante de la solidez de mis estimaciones es el autor de la monografía de donde se han tomado los datos primarios, Alfredo Lagunilla, brillante historiador económico español y acreditado experto en finanzas exiliado en México tras la guerra civil. ${ }^{1}$ Con todo, se han contrastado y completado sus guarismos con los publicados por la prensa mercantil. Más allá de lo que, con base en el trabajo de Lagunilla, se ha hecho en la recopilación de datos, no se puede llegar.

El índice es anual, he de precisar en un primer término. No es posible efectuar un índice con una periodicidad menor porque raramente cotizaron los valores que componen la muestra a lo largo de todo el ejercicio,

\footnotetext{
${ }^{1}$ Lagunilla, responsable del Servicio de Estudios de Banamex durante años, ya no es el autor sólo de las primeras monografías de historia económica mundial y de México escritas en español, sino de la primera sobre la historia financiera de ese país y de la propia Bolsa. Lagunilla fue uno de los especialistas en mercado de valores más reputado de América Latina. Sin embargo, su obra ha sido menospreciada a tal punto que Maurer (2002) no la emplea en su estudio sobre el sistema financiero entre 1876 y 1932, lo que obviamente se deja ver en los resultados de su trabajo.
} 
debido a las contingencias políticas y económicas de las que aquí se da cuenta.

En un segundo término, puede suscitar una discusión la elección del ponderador de los subíndices, el capital suscrito, con el supuesto implícito (asumido en la elaboración de algunos índices contemporáneos al uso, por lo razonable) de que hay una relación directa entre el capital social y la negociación de acciones. ¿Es acaso posible que se vendan muchas acciones de empresas con poco capital? ¿Es común que la trayectoria de los precios de las acciones de una empresa, con gran volumen de cotización, sea distinta a la del resto sin provocar un cambio de tendencia? Obviamente, y en ambos casos, no.

Es más, podemos seguir discutiendo, como sucedió en el caso de las cestas de bienes en la construcción de los niveles de vida, sobre el peso que atribuir a cada acción, sí. Una pérdida de tiempo. Como en el caso citado, el uso de medias aritméticas no ponderadas arrojaría resultados similares y tendencias idénticas. Lo que se proporciona es un cálculo mucho más depurado y concluyente que una secuencia pretenciosa de adjetivos, lo único disponible hasta la fecha en el estudio de la Bolsa de México en el periodo, por más que estén en inglés. De hecho, el Dow Jones se construye sin ponderación alguna.

Por otra parte, y para dar mayor solidez estadística a estos argumentos, se ha tenido en cuenta la cotización de los títulos mexicanos en el exterior. Es decir, se ha estimado su grado de valoración tanto por los inversores extranjeros como nacionales. La gráfica 4 presenta los cálculos que indican el grado de solvencia percibida de la economía mexicana en su conjunto.

FUNDACIÓN, AUGE MINERO Y PRIMERAS CRISIS BURSÁTILES (1885-1909)

Las primeras operaciones de compraventa de acciones en la Ciudad de México se fechan en torno a 1850, cuando en otras capitales hispanoamericanas fueron comunes desde 1820 . El retraso obedeció a las reticencias del Estado. El gobierno no sólo tenía pavor a la especulación bursátil y a las crisis financieras que, entendía, le eran inherentes; temía también que la venta de títulos de renta dificultase su acceso al crédito, imprescindible por la debilidad del régimen impositivo. Por esta razón, las transacciones con acciones se efectuaron en la clandestinidad, en un portal, en un carruaje o en una taberna, durante más de tres décadas (Lagunilla-Iñarritu, 1973, p. 3).

No significa esto que México no contase con un mercado de valores, sino que no estaba organizado formalmente. Así sucedió en el resto de América Latina. Pero las restricciones fueron levantadas mucho antes en 


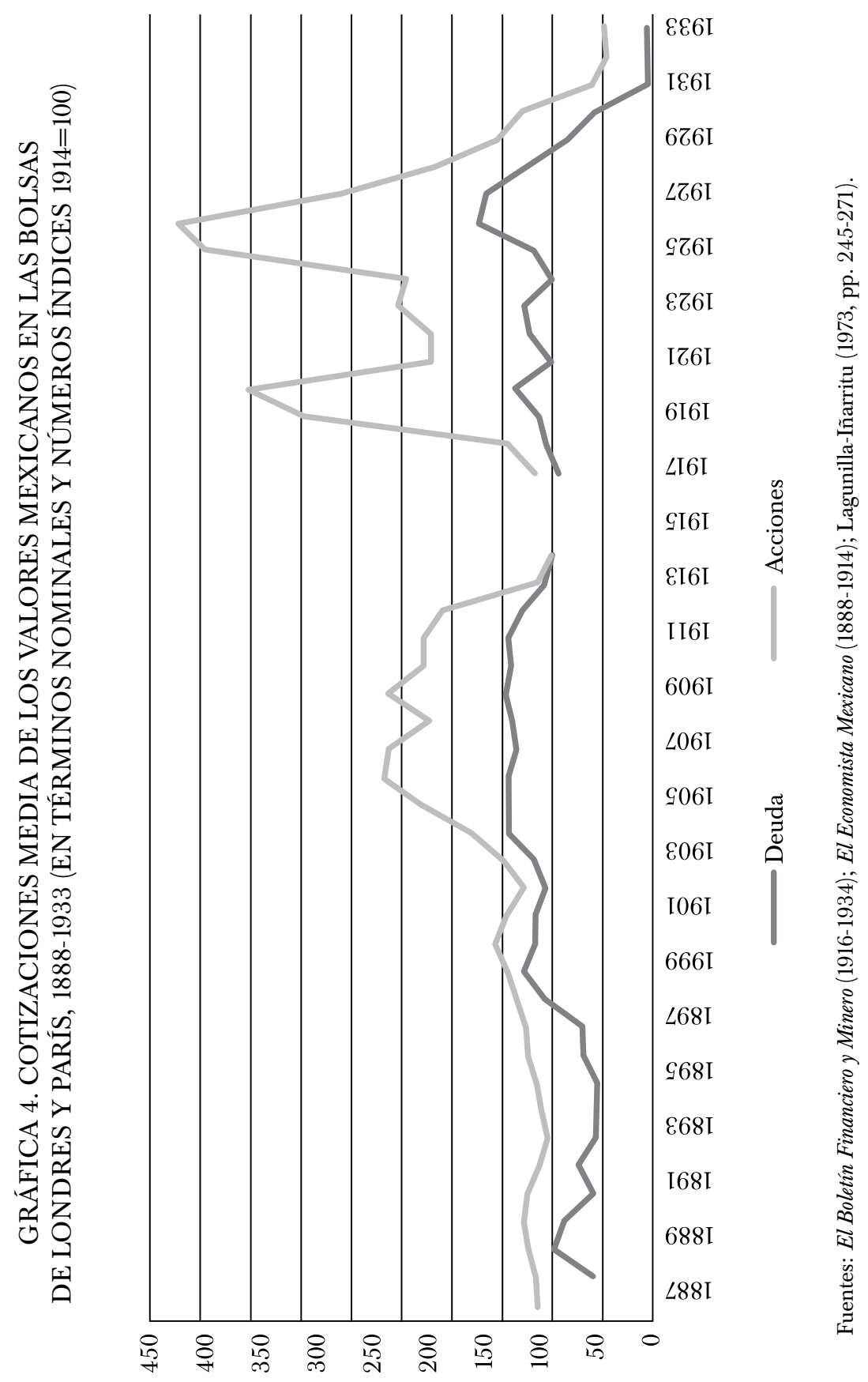


Río de Janeiro (1848), Buenos Aires (1854), La Habana (1855) y Montevideo (1867).

Es menester detenerse un instante en la explicación de lo tardío de su nacimiento. La creación de una institución formal que amparase estas negociaciones en un país sacudido durante 60 años por las guerras civiles, el caudillismo, las revueltas y las ocupaciones extranjeras resultaba poco menos que una quimera. El mercado de valores es mucho más sensible que la banca a los conflictos y a la inestabilidad política. La incertidumbre y la ausencia de información atemorizaban a los ahorradores. Sin lugar a dudas, la bolsa de Guayaquil (1870) tuvo una vida efímera por estas causas. Conviene también traer a colación en esta interpretación un factor olvidado, a pesar de su importancia, que tiene que ver con los aspectos normativos. México, debido a la inestabilidad política, dispuso de un Código de Comercio en 1884 (con un retraso de dos décadas respecto de las otras grandes economías latinoamericanas). No hubo regulación de las transmisiones de acciones hasta entonces. La Bolsa requería de la cobertura y seguridad jurídica que confería la codificación. Al final, los gobiernos auspiciaron el nacimiento de las Bolsas en América Latina, resultado de una conversión de la deuda externa y, por tanto, de una imposición explícita de los acreedores, a fin de colocar, al menos, los títulos de deuda interna. Pues bien, México estuvo en suspensión del pago de la deuda desde 1827 hasta mediados de la década de 1880 .

El alumbramiento de la Bolsa de México, en cuanto tal, fue el resultado de la política económica liberalizadora emprendida por Porfirio Díaz, presidente de la república desde 1876. Su gobierno vio con otros ojos el intercambio de valores tras la crisis financiera de 1884, dada la inutilidad de las prohibiciones (Cárdenas y Ángel, 2011, pp. 31-32; Costeloe, 2003; Lagunilla-Iñarritu, 1981, pp. 41-42; Marichal, 1997, pp. 129-130; Maurer, 2002, pp. 24-25). El dictador consideró entonces la Bolsa como un instrumento imprescindible para atraer a capitalistas extranjeros y avanzar en la modernización económica del país.

En efecto, las empresas mexicanas, en especial las mineras, padecían entonces problemas de financiación. Los pocos bancos existentes facilitaban préstamos exclusivamente a grandes propietarios agrarios. El hipotecario se obtenía a un interés muy elevado (Levy, 2012). Las compañías ferroviarias, que en otros países de América Latina estimularon el surgimiento de la Bolsa gracias a las subvenciones estatales, no tenían que encarar estas dificultades (Lagunilla-Iñarritu, 1973, pp. 38-39).

El reconocimiento a la legalidad de tales operaciones obedeció también a las necesidades de la Hacienda, tal y como señalaba antes. En efecto, tras el arreglo de la deuda con el Reino Unido y la reordenación de la interior en junio de 1885, el gobierno optó por colocar las nuevas emisio- 
nes de bonos en el mercado formal de capitales (dos títulos de renta fija a $3 \%$ y $5 \%$ ) y prescindir de los prestamistas, los llamados agiotistas (Costeloe, 2003; Marichal, 1993).

Sin embargo, México constituyó una anomalía en el contexto latinoamericano. El gobierno, en lugar de instituir una Bolsa propiamente dicha, permitió en 1885 que cuatro empresas privadas dirigidas por corredores, la más potente de ellas la Agencia Mercantil, facilitasen el encuentro de vendedores y compradores. Es decir, se limitó a dar cobertura legal a unas negociaciones antes practicadas literalmente a escondidas, pero sin mayor implicación de las instancias públicas. Un error que sentó precedentes.

A pesar de esta singularidad, los resultados superaron las expectativas del ejecutivo. De hecho, hasta un centenar de empresas extractivas resolvieron vender sus acciones en uno de estos locales. Por entonces, en la Bolsa de Buenos Aires sólo lo hacían media docena y 25 en La Habana.

$\mathrm{El}$ sustento real de esta euforia minera fue muy endeble, a diferencia de lo sostenido por Haber (1989, pp. 79-80). Cierto es que el auge exportador desató en la segunda mitad de la década de 1880 una fiebre inversora en el sector (Solís, 1997, p. 97) (véanse gráficas 1, 2 y 4). La consideración de lo acaecido en Nueva York desvela la pujanza bursátil vivida en México y la apreciación de los valores que provocó (véase gráfica 5). Las compañías británicas ofrecían acciones con una rentabilidad de $15 \%$ y dividendos de $100 \%$. La irrupción de capital francés en búsqueda de nuevos yacimientos infló aún más la burbuja (Lagunilla-Iñarritu, 1973, pp. 16-17). Los precios de las acciones se multiplicaban por cuatro en un solo día. Las compañías mineras emitieron acciones sin otro fin que obtener beneficios extraordinarios en las transacciones de compraventa.

No obstante, se trataba de operaciones meramente especulativas que dieron una vitalidad artificial a la Bolsa. El convencimiento generalizado (sobre todo en el exterior) de que México era un Dorado minero sin explotar por la indolencia de los españoles llevó a muchos comerciantes logreros de poca monta, y menos escrúpulos, a registrar compañías mineras titulares de vetas con posibilidades productivas inciertas (como ya había sucedido antes en otros países latinoamericanos), así como a emitir acciones que se colocaron en la Bolsa con precios por encima de la par. Al cabo de unos meses, estas compañías y sus promotores se esfumaban. Pero no todo fue dinero fácil y oportunismo. Grandes firmas mineras como San Rafael, al tiempo que el Banco Nacional de México y el Banco de Londres, pudieron atender sus necesidades de capital gracias a la Bolsa.

La combinación de euforia bursátil con el endeudamiento público tuvo efectos letales en el corto plazo. En efecto, animado por el fervor minero, el gobierno de Porfirio Díaz había tomado a préstamo de Gibbs \& Son, Selimann y Dredsner Bank, Glyn, Mills \& Co., sumas muy elevadas 


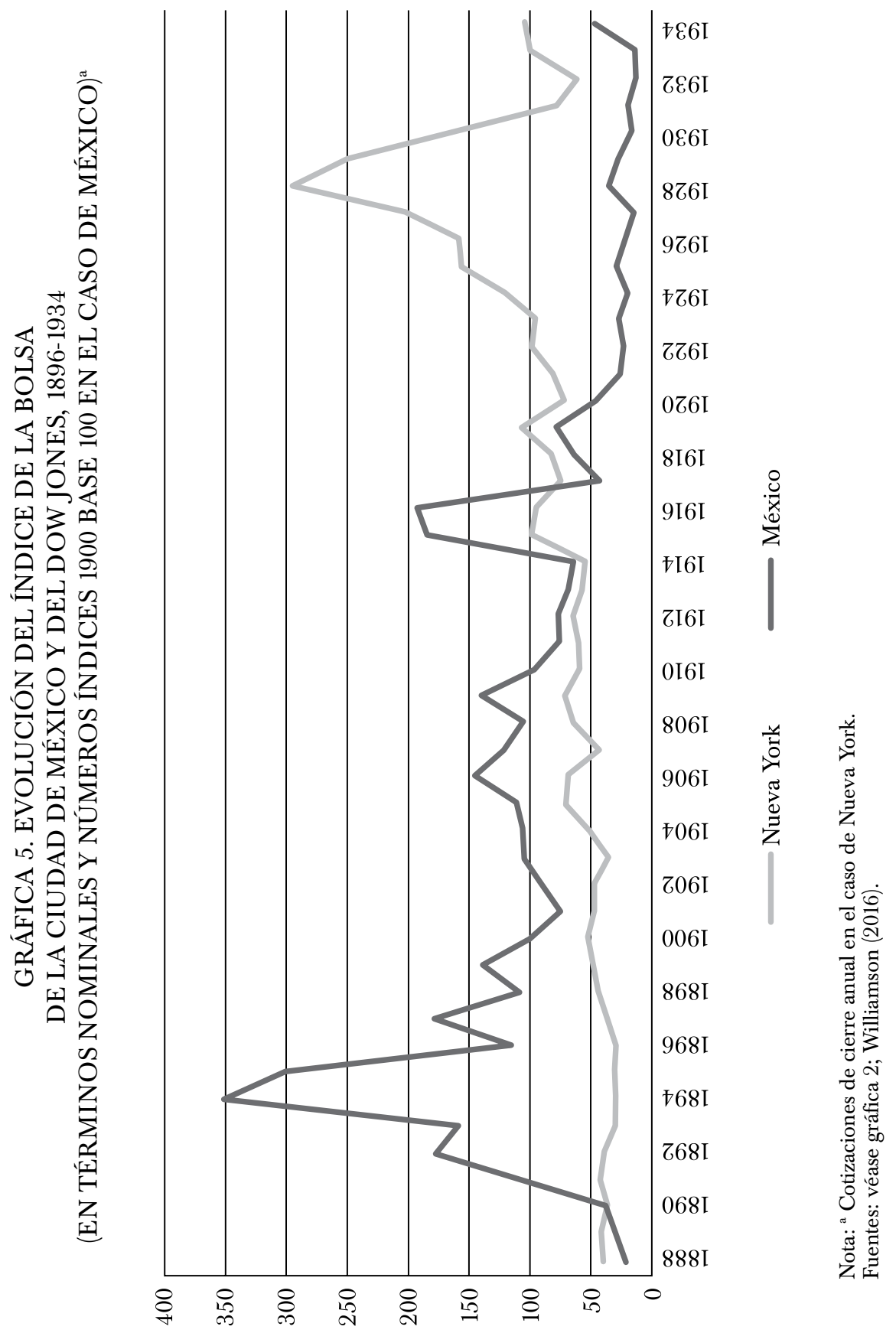


entre 1890 y 1893 para costear la construcción del ferrocarril. Para tal fin, emitió deuda externa garantizada con $25 \%$ de los impuestos que gravaban la exportación de plata, a un tipo de interés de $6 \%$, muy moderado en relación con los países vecinos (en La Habana se emitían bonos a 8\%) y rentabilidad de 9\% (Corporation of Foreign Bondholders [CFB], 1895, pp. 212-213).

Así pues, convivían en un mercado de capitales ajeno a lo que estaba sucediendo en el resto del mundo (sobre todo tras la crisis de la Bolsa de Nueva York en mayo de 1893), acciones sobrevaluadas y bonos que devengaban rendimientos altísimos. La burbuja acabó por estallar a comienzos de 1894, tras la reducción del capital de las compañías mineras, consecuente con la evolución del precio de la plata (véase gráfica 6). Estas operaciones de split provocaron el desplome de la cotización de las acciones (véanse gráficas 1 y 2). La evidente imposibilidad del Estado de atender obligaciones contraídas en el exterior acrecentó el temor de los inversores, que se desprendieron apresuradamente de sus títulos (véase gráfica 3).

A pesar de darse por segura y ser anticipada esta situación por los mercados, México no se declaró finalmente en suspensión de pagos gracias a la pericia del responsable de su política fiscal. A lo largo de 1895 el secretario de Hacienda Limantour, nombrado dos años atrás, acabó con el desorden financiero y la insolvencia que comprometían la estabilidad económica del país. En primer lugar, a finales de ese año decretó una conversión forzosa de toda la deuda externa a un título único al 5\%, conversión muy bien recibida por los acreedores (véanse gráficas 3 y 4 ).

En segundo lugar, acometió una profunda renovación del mercado de valores. La existencia de cinco instituciones donde intercambiar acciones no era operativa ni viable porque provocaba distorsiones en la difusión de información. Convenía la unificación en una Bolsa cuyo funcionamiento fuera regido por la ley. En suma, había llegado el momento de mejorar la definición de unos derechos de propiedad en materia financiera, hasta entonces difusos y permisivos con la especulación (Haber, Maurer y Razo, 2003).

En octubre de 1895 se constituyó a tal fin la Bolsa Mercantil de México, con un capital de 60000 pesos (Solís, 1997, p. 94). En ella concurrió medio centenar de corredores que percibían comisiones de entre 1 y $2.5 \%$ (Lagunilla-Iñarritu, 1973, pp. 3-11).

Gracias a la modernización institucional y a la repentina apreciación de la plata, la euforia financiera volvió a la Bolsa (véanse gráficas 1 y 6). Pero las reformas de Limantour atenuaron, en parte, la presión de la demanda de los valores mineros. Ahora resultaba también atractiva y más segura la inversión en títulos de renta fija, dentro y fuera del país (véanse gráficas 3 y 4). Las empresas mineras culparon al secretario de Hacienda 


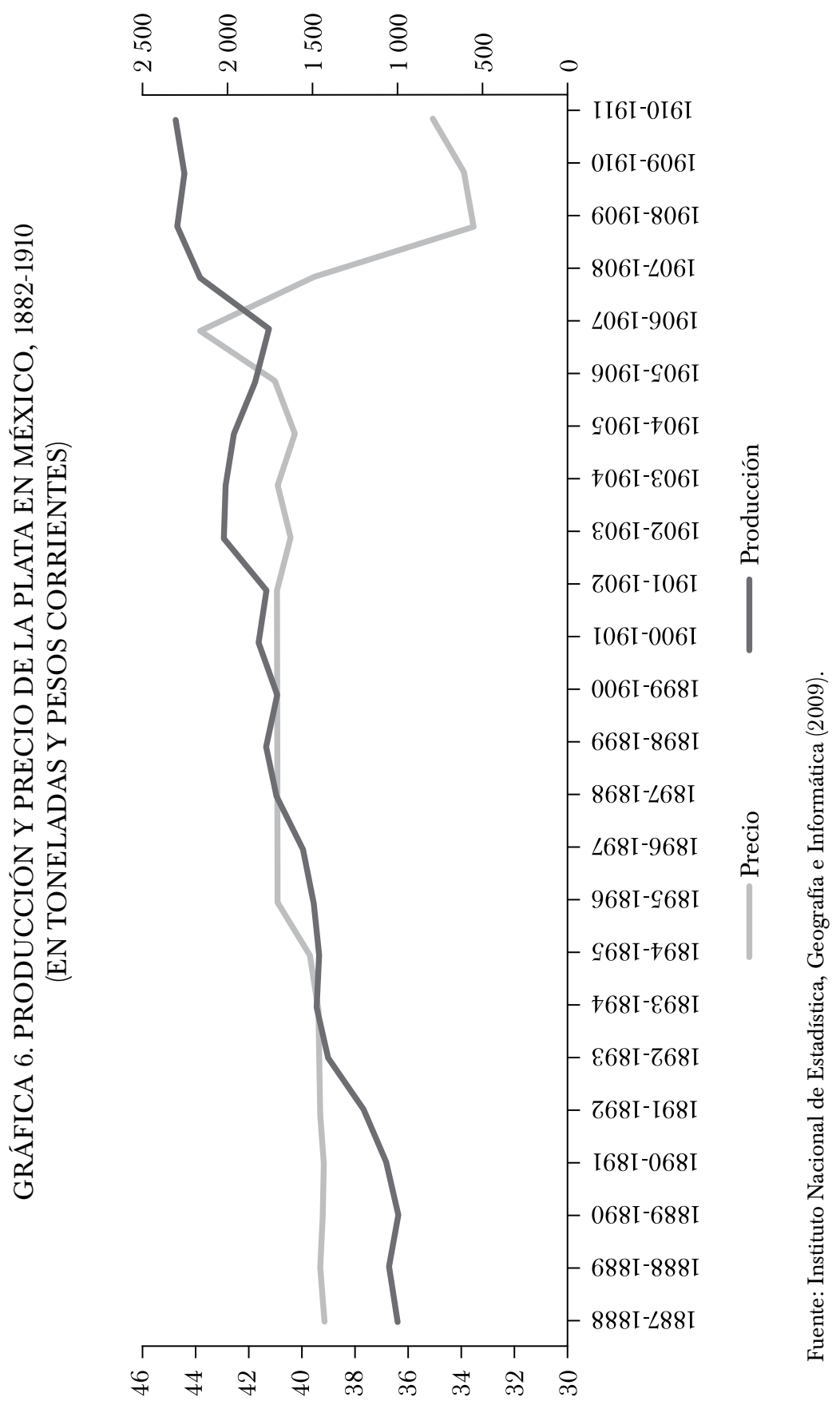


-no sin razón- de este enfriamiento de su mercado. Resolvieron, por ello, crear una Bolsa propia en abril de 1896 (Solís, 1997, pp. 94-95). Esta separación no es exclusiva de México. En otros países, como Uruguay, también se produjo. Los oferentes de acciones desconfiaron del interés real de unos gobiernos, endeudados y apremiados por vender sus bonos, en favorecer la negociación de títulos de renta variable. Así pues, fue común en el conjunto del continente que, tras la crisis Baring de 1890, los capitalistas prefiriesen negociar en asociaciones propias o en instituciones patronales.

El mercado de acciones no sólo sufrió este divorcio. La caída del precio de la plata en el mercado mundial en 1898 forzó la de los índices bursátiles mexicanos (véanse gráficas 1, 2 y 6). Adicionalmente, esta depreciación dificultó el pago de la deuda externa, garantizada en la recaudación de los derechos ad valorem de exportación de mineral. Los apuros por honrar la deuda y el contagio de la crisis en la Bolsa de Nueva York de 1899 provocaron una caída ostensible de las cotizaciones en la Bolsa de la ciudad de México (véanse gráficas 1, 2 y 5). Las oscilaciones del índice de precios de las acciones y su trayectoria tan dispar respecto a la del producto interno bruto (PIB) revelan que la Bolsa y la economía mexicana transitaban ya por caminos separados (véase gráfica 7), o lo que es lo mismo, que el aumento del ahorro no tenía mayor repercusión en la actividad bursátil.

Limantour tuvo que intervenir mediante una nueva conversión de la deuda externa, ahora unificada en bonos pagaderos en plata a 5\%, emitidos a $64 \%$, es decir, con una rentabilidad de $7.4 \%$. Su pago quedó garantizado en dos tercios de la recaudación de las exportaciones de mineral, controladas, en la práctica, por el mayor tenedor de los casi 27000000 de libras emitidos, Speyer \& Co. (Lagunilla-Iñarritu, 1981, pp. 72-73; CFB, 1899, p. 241).

Sin embargo, los inversores mexicanos no aprendieron la lección. La euforia volvió de nuevo a la Bolsa a comienzos del siglo $\mathrm{Xx}$, por culpa ahora de la demanda de acciones emitidas por los bancos. Antes, en 1897, Limantour había dictado la Ley de Bancos de Emisión con el fin de facilitar la apertura de estas entidades en cada estado e incrementar los instrumentos de pago. Para impulsarlo obligó, por ley, al reparto mínimo de $25 \%$ de los beneficios entre los accionistas en forma de dividendos. Los bancos obtuvieron utilidades muy elevadas, no con la emisión, sino con la concesión de préstamos a largo plazo (a pesar de estar prohibidos), con lo que arrebataron este lucrativo negocio a los usureros locales. La adopción del patrón oro en 1905, con la que Limantour culminó sus reformas, animó todavía más a la compra de estos valores (Lagunilla-Iñarritu, 1981, pp. 41-44).

Ante el estancamiento del precio de la plata, muchos inversores prefirieron las acciones de los bancos en lugar de las correspondientes a las 


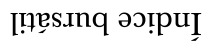

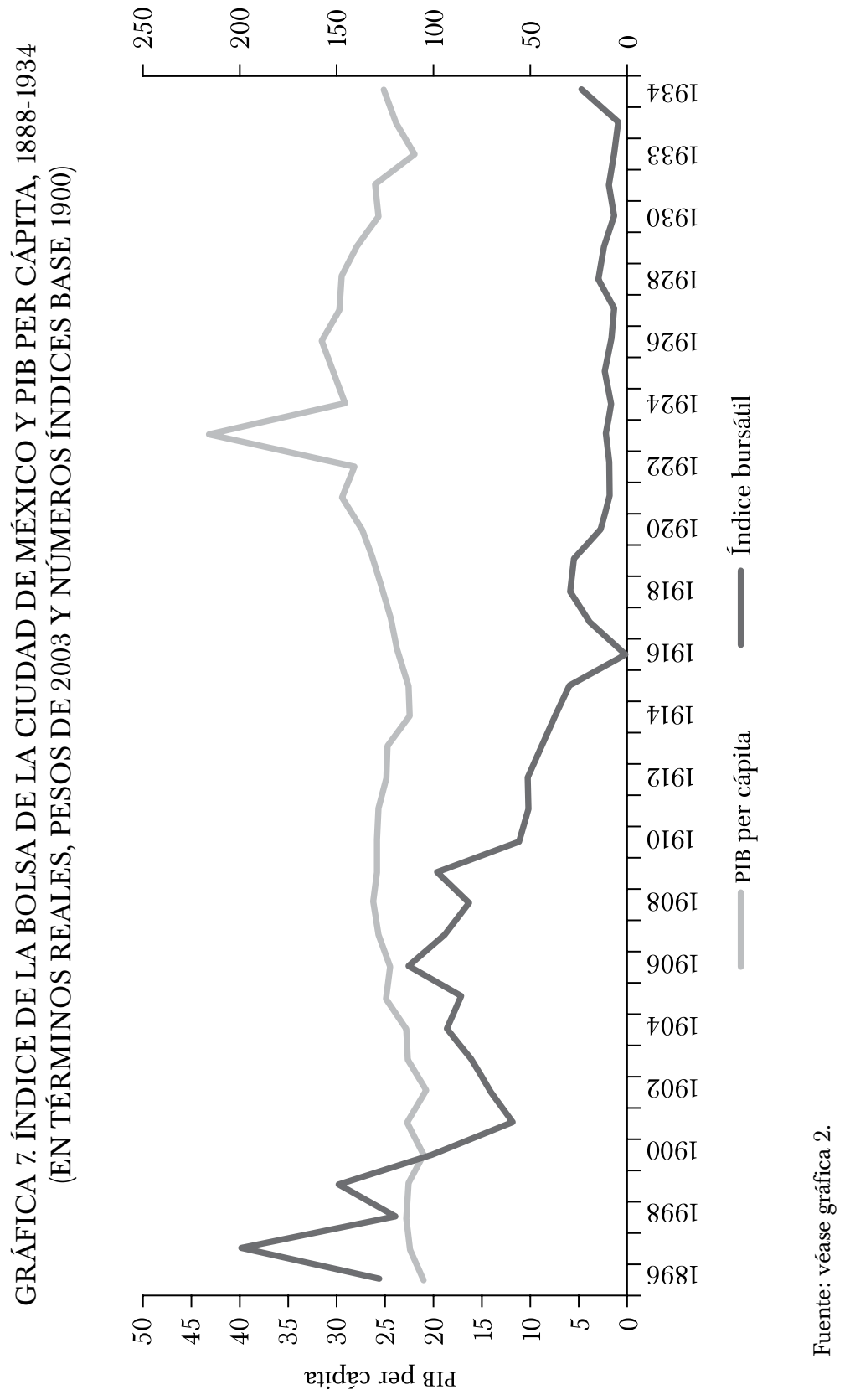


compañías mineras (véanse gráficas 2 y 6). No en balde los dividendos repartidos por estas firmas en promedio y en pesos corrientes pasaron de 138.1 en 1899 a 31.6 en 1905 (Lagunilla-Iñarritu, 1973, pp. 334-336). El fin de esta anarquía institucional en el mercado de valores animó a concurrir en él a grandes compañías manufactureras, como la Fundidora de Monterrey, la tabaquera capitalina El Buen Tono, o las firmas textiles en las proximidades de la ciudad de México y, sobre todo, de Orizaba, en el estado de Veracruz. De hecho, las empresas extractivas tuvieron que buscar refugio en las Bolsas de Londres y Nueva York debido a la carencia de compradores en la de México (Macedo, 1905, p. 126).

Los productores de plata, de nuevo, atribuyeron sus dificultades al endeudamiento exterior y a otros factores exógenos, en particular a la caída del precio del café. De hecho, en 1900, primero, y en 1906, después, volvieron a organizar una Bolsa propia (Lagunilla-Iñarritu, 1973, pp. 6 y 48). La situación obligó al gobierno a actuar. En enero de 1907 dispuso la habilitación de una única Bolsa de Valores para poner fin a los caprichos del lobby minero que tanto daño hacía al mercado de capitales (LagunillaIñarritu, 1973, p. 67).

Pero justamente esta normalización financiera facilitó la difusión del pánico estadunidense en octubre de ese año (Cavazos, 1976, p. 58; Reinhart y Rogoff, 2008, p. 402; Romero, 2009) (véase gráfica 5). También lo hizo el sempiterno problema de los bonos. El aumento del endeudamiento exterior desde 1903 (véase gráfica 8) para sufragar los gastos en educación y suministro de agua en la capital federal llegó a tal extremo que, en el otoño de 1907, los inversores daban por segura una nueva conversión, obligada por el descenso en las rentas de aduanas, a causa de la del comercio exterior (véase gráfica 9). Aunque finalmente no se produjo, de nuevo gracias a la destreza de Limantour, hubo una retirada masiva de fondos de los bancos (CFB, 1908, p. 277). Atemorizados, los hombres de negocios se parapetaron en la deuda pública, a juzgar por la evolución de su cotización (véase gráfica 3).

Sin embargo, la crisis fue poco intensa y duradera (véanse gráficas 2, 4 , 7 y 9). Como sucedió en 1894, y en contra de los augurios de los corredores, México pudo atender sin dificultades el servicio de la deuda. Es cierto que el abaratamiento de la plata y la minoración de las exportaciones (véanse gráficas 6 y 9) trajeron consigo el momentáneo declive económico del país (Romero, 2009). Sin embargo su reflejo en una Bolsa, cada vez menos dependiente de los negocios minerales, fue tenue. Ahora las firmas manufactureras mencionadas marcaban, en buena medida, el paso. $\mathrm{Y}$ el suyo era firme. 


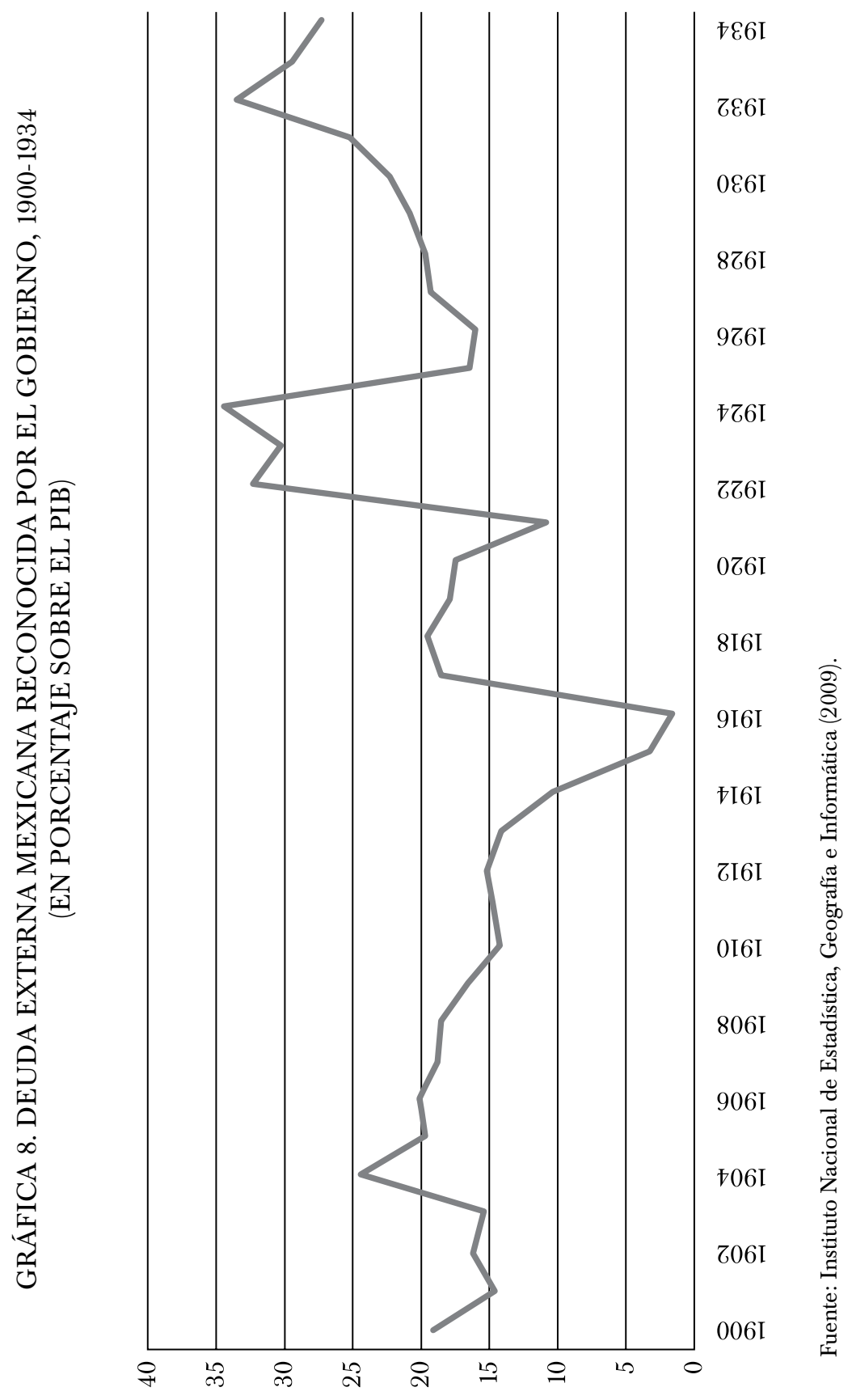




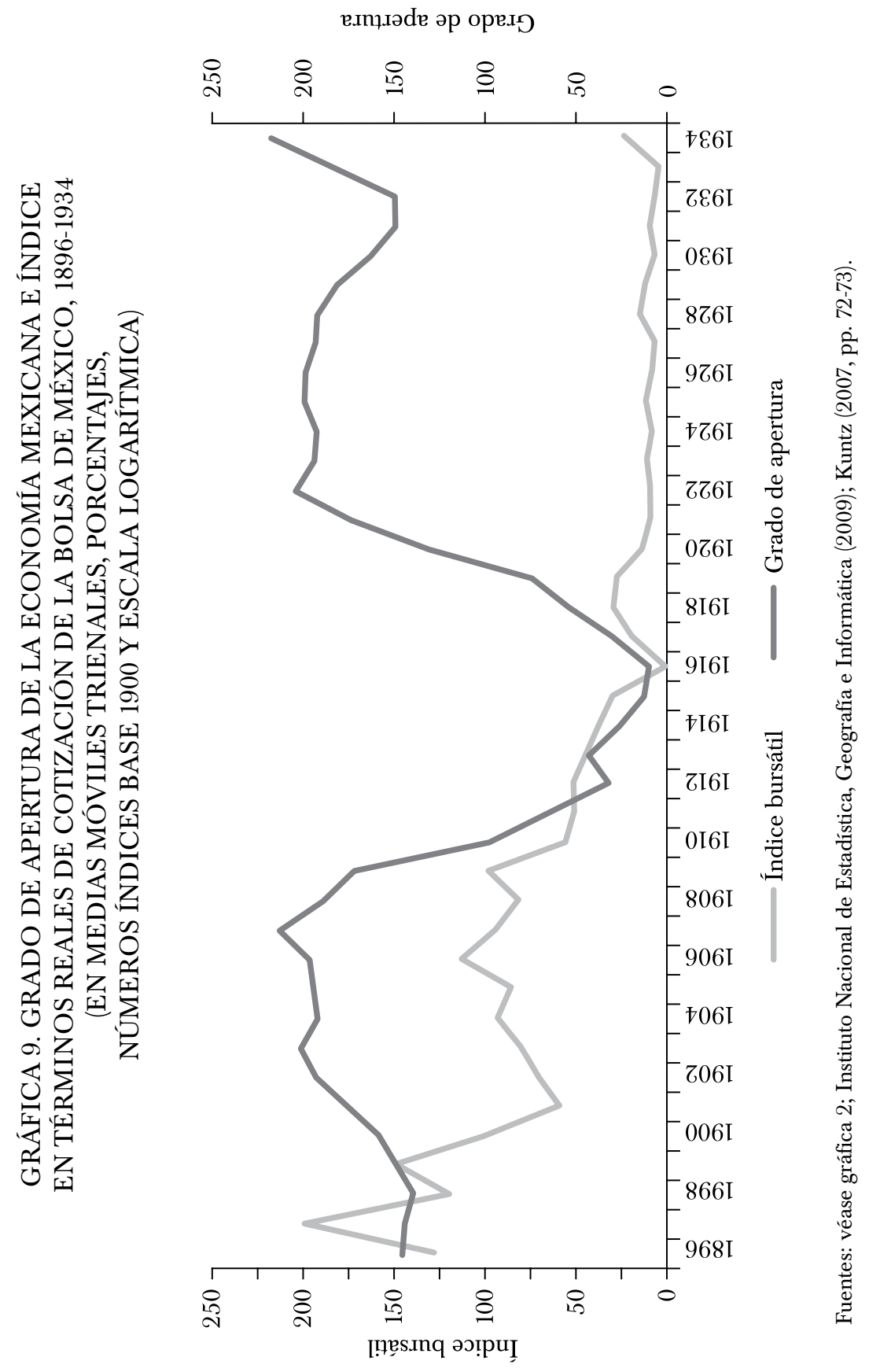




\section{LA BOLSA Y LA REVOLUCIÓN (1910-1920)}

La crisis de 1907, por más efímera y fugaz que fuera, constituyó el preludio financiero de la revolución, cuyas consecuencias adversas en el mercado de capitales pervivieron durante décadas (Cárdenas y Manns, 1989; Cavazos, 1976, pp. 59-63; Haber, Maurer y Razo, 2003, pp. 93-123; Paz, 2006) (véanse gráficas 1, 6 y 10). La comparación con la Bolsa de Nueva York y sus registros es, de nuevo, pertinente y esclarecedora (véase gráfica 5).

A comienzos de 1910 la situación económica dio ciertas muestras de mejoría, después de tres años de estancamiento. Tanto es así que Limantour no encontró dificultades para contratar en París un empréstito por un valor de 560500000 francos para aliviar las premuras de la Hacienda, muy resentida por el descenso de los impuestos que devengaba la exportación, particularmente de henequén. Gracias a ello pudo mantener el programa de obras públicas regulado en la Ley de 1899 (Lagunilla-Iñarritu, 1981, pp. 72-73).

No obstante, el estallido de la revolución el 20 de noviembre de 1910 abortó la recuperación. Su líder, Francisco Madero, un moderado con una excelente formación académica, suscitó la confianza de los inversores extranjeros, como demuestra la cotización de la deuda exterior en París y Londres (Méndez, 1996) (véase gráfica 4). Incluso recibió ayuda financiera de Speyer \& Co. (The New York Times, 26 de julio de 1906). De hecho, a comienzos de 1911, Madero redimió parte de la deuda externa emitida en 1899 justamente para ganarse la confianza de los bonistas europeos (CFB, 1911, p. 252). Por el contrario, la actitud de los empresarios mexicanos con el nuevo gobierno fue mucho más beligerante, de ahí la caída de las cotizaciones bursátiles (véanse gráficas 1 y 2).

Los levantamientos contra el gobierno, unidos a las huelgas y a la supresión del tráfico ferroviario, frustraron sus planes de modernización económica y de regeneración política. Para costear simultáneamente sus inversiones en infraestructuras y los gastos militares, la Hacienda emitió deuda por un valor de 18000000 de dólares cuya colocación en el mercado interno tuvo un efecto de expulsión inmediato (CFB, 1913, p. 218).

La situación empeoró tras el golpe de Estado del 9 de febrero de 1913, cuando se inició la denominada "decena trágica" con el sangriento final del ajusticiamiento de Madero. La gestión económica del nuevo mandatario, el dictador Victoriano Huerta, apoyado al principio por algunos sectores empresariales, no merece más adjetivo que el de desastrosa. De entrada, tuvo que emitir en mayo de ese año un empréstito de 20000000 de dólares para atender los servicios de la deuda y liquidar los compromisos con Speyer \& Co. A pesar de que la emisión sólo estaba garantizada en $20 \%$ de los impuestos a la exportación y no en 39\%, como se compro- 

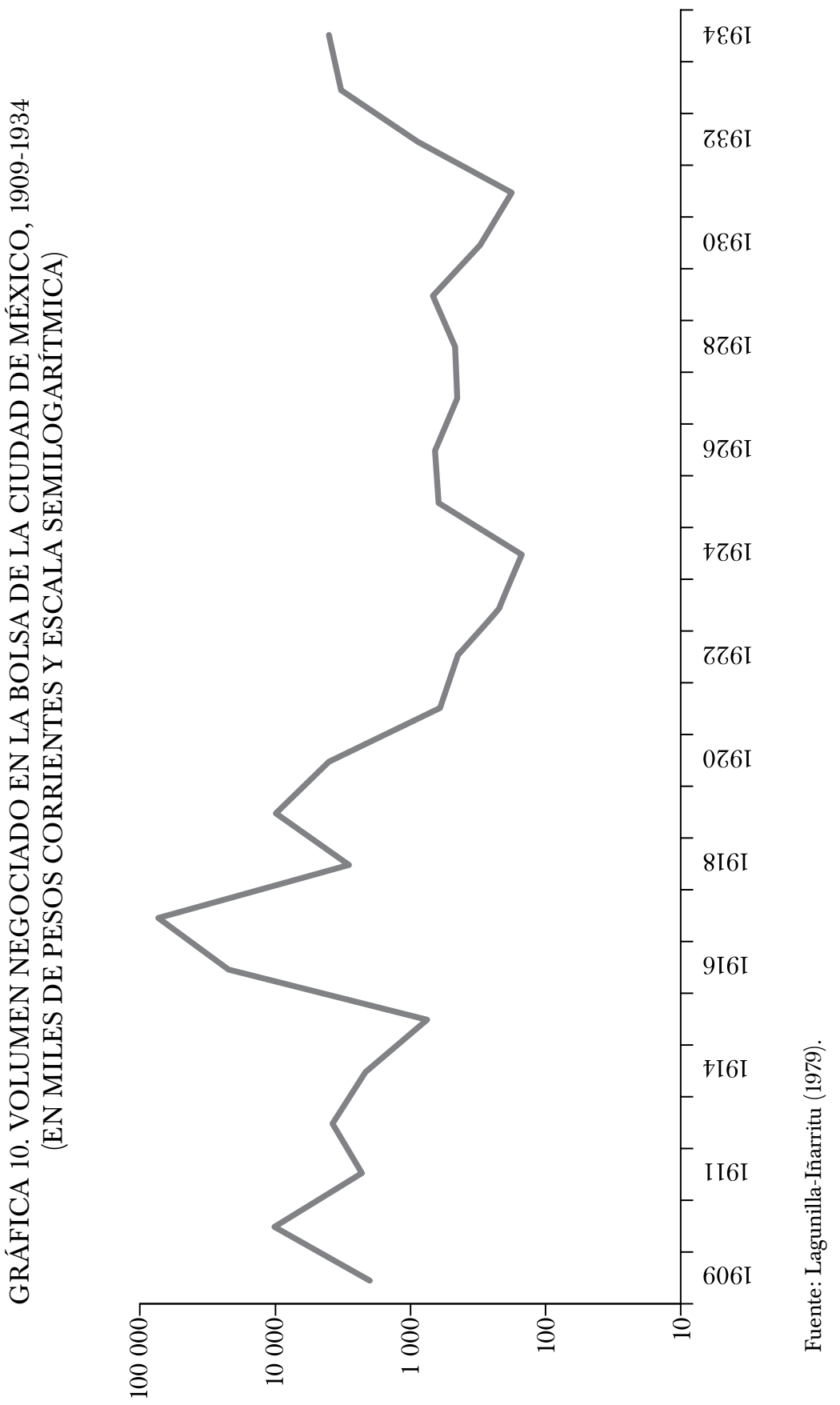
metió el gobierno (el 80\% restante estaba ligado a emisiones anteriores), los títulos se colocaron con relativa facilidad en Londres y, sobre todo, en París, a 96\%. Pero Huerta empleó buena parte de los recursos obtenidos en amortizar obligaciones de las compañías ferroviarias y no en aminorar la deuda. Conocida la maniobra, los tenedores extranjeros se desprendieron de ella ofreciéndola a $85 \%$. En estado de total insolvencia y carente de todo crédito en el exterior, México declaró la suspensión de pagos en 1914 (CFB, 1914, 1915). Finalmente Huerta dispuso el abandono del patrón oro. Ante tales desatinos y calamidades, las Bolsas europeas prohibieron la negociación de los títulos de renta variable mexicana (Bazant, 1968, pp. 174-200) (véase gráfica 4).

Así, las grandes empresas nacionales vieron cerradas sus puertas a la financiación exterior en unos momentos en que obtenerla en el país era casi imposible a causa de las corridas bancarias y de la propia inactividad de la Bolsa (véanse gráfica 10 y cuadro 1). Estas calamidades, unidas a la caída de las exportaciones, causaron el descenso de los índices bursátiles, muchísimo más acusado que el del PIB (véanse gráficas 1,7 y 9).

La llegada al poder de Venustiano Carranza, en julio de 1914, y el aumento del comercio exterior que siguió al estallido de la primera guerra mundial aliviaron las expectativas empresariales (quince compañías volvieron a cotizar en la Bolsa) (véanse gráficas 9 y 10). De ahí resultó el crecimiento que experimentaron las cotizaciones, aunque se debió sobre todo a la fuerte inflación ocasionada tras la emisión descontrolada de billetes sin respaldo en oro y el reconocimiento de los emitidos por las tropas insurgentes, salvo las de Pancho Villa (Lagunilla-Iñarritu, 1973, p. 90) (véanse gráficas 1 y 2).

Sin embargo, en pleno conflicto en Europa, Carranza cambió el rumbo financiero de la revolución. El presidente sancionó la moratoria en el pago de la deuda y prácticamente incautó los bancos, que fueron obligados a sostener a las guarniciones con sus escasas reservas. El 6 de junio de 1916 clausuró la Bolsa, tras culparla de la "desenfrenada especulación", alentada por la apreciación de la plata (véase gráfica 11), que amenazaba, en su criterio, el éxito de la revolución (Reina, 1958, p. 26; Zebadúa, 1994, pp. 109-116). Transcurrido un mes fue refundada, si bien ahora sometida a una férrea tutela estatal.

Así pues, la medida de Carraza supuso un auténtico punto de inflexión en la historia financiera de México. Desde entonces el gobierno tuvo a la Bolsa como un mero intermediario en la realización de las operaciones de mercado abierto, con el fin de colocar deuda y detraer billetes en circulación. La cotización de acciones quedó sometida a un severo escrutinio por parte de la Secretaria de Hacienda, a la que competía ahora la admisión de nuevos emisores y el registro de las transacciones. 
CUADRO 1. EMPRESAS COTIZADAS EN LA BOLSA DE MÉXICO (CON NEGOCIACIÓN REGULAR)

\begin{tabular}{lc}
\hline Año & Empresas \\
& \\
1895 & 111 \\
1900 & 92 \\
1910 & 117 \\
1914 & 43 \\
1920 & 45 \\
1930 & 23 \\
\hline
\end{tabular}

Fuentes: Excélsior (1919-1930); Lagunilla-Iñarritu (1973, pp. 245-271).

A consecuencia de este control estatal y con la caída progresiva del precio de la plata (véase gráfica 11), la Bolsa entró en una situación de total abatimiento (véase gráfica 10). Los bancos locales (como el de San Luis Potosí, Tamaulipas, Coahuila y Nuevo León), junto con empresas manufactureras muy señaladas (como las dos grandes textileras, San Ildefonso y la Compañía Industrial de Orizaba) se retiraron del parqué (véase cuadro 1). Carranza consiguió, en efecto, acabar con las burbujas especulativas, pero a costa de desestimular la negociación de acciones y ahuyentar a los corredores.

Por el contrario -tal y como pretendía el mandatario- la cotización de los bonos alcanzó niveles elevados, sobre todo en el exterior (véanse gráficas 3 y 4). La promesa transmitida en febrero de 1917 de que México honraría la deuda externa, cifrada ya en 64700000 libras (sin incluir los bonos hipotecarios emitidos por el Estado), calmó a los tenedores foráneos (CFB, 1917, p. 1917).

De hecho, en 1918 gracias a este anuncio y, sobre todo, al aumento de las extracciones de petróleo, convertido en el principal componente de las exportaciones, la Bolsa conoció cierta reanimación, como la propia economía mexicana, materializada no tanto en los índices bursátiles cuanto en el volumen negociado (véanse gráficas 2,7 y 10). La aplicación de las primeras medidas de reforma fiscal contempladas en la Constitución de 1917 y el subsiguiente saneamiento del Estado contribuyeron a ello (Riguzzi, 2001). Incluso los valores mexicanos volvieron a cotizar en los mercados europeos (véase gráfica 4), a pesar de que el país seguía técnicamente en suspensión de pagos.

Los menguados efectos positivos del conflicto se diluyeron con la crisis financiera de 1920-1921 (véanse gráficas 1, 2, 3 y 4), particularmente 
[ฺฺ:s.nq әว!puI
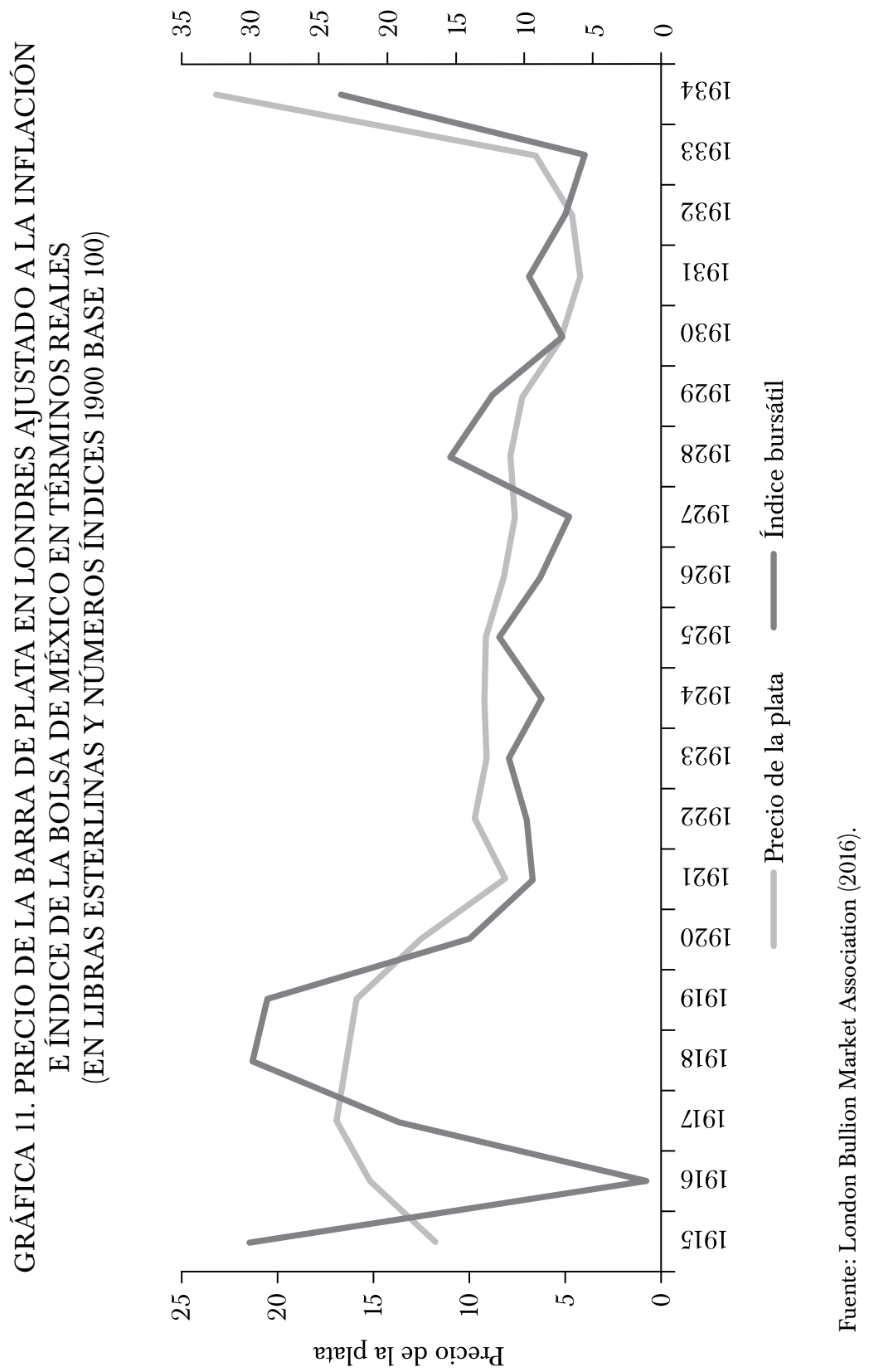
intensa en México por la caída del precio de la plata y de la producción petrolera (véanse gráfica 11 y Vega, 1999). El incumplimiento de los compromisos de México con sus acreedores avivó las turbulencias financieras. De nuevo grandes empresas, sobre todo petroleras e industriales de La Laguna (como La Jabonera), un núcleo fabril emergente que sólo encontró auxilio financiero en la Bolsa durante un breve lapso, cesaron la emisión de acciones.

Carranza trató de atajar el pánico reiterando en febrero el compromiso de su gobierno de pagar la deuda externa y devolver los ferrocarriles, nacionalizados durante la revolución, a sus antiguos propietarios. Pero su asesinato en mayo malogró todo intento de recuperar la credibilidad exterior del país. La Bolsa entró en un periodo de total abatimiento mientras que los índices de cotización registraron mínimos históricos (véanse gráficas 1,2 y 10$)$.

\section{DEFLACIÓN, INSOLVENCIA Y AGONÍA DE LA BOLSA, 1921-1928}

Cuando Álvaro Obregón se hizo cargo de la presidencia del país en diciembre de 1920, a causa de los gastos realizados durante la revolución, debía atender la deuda por un valor de 940700000 pesos y los intereses por 215700000 pesos (véase gráfica 8) (CFB, 1921, p. 239). México no tenía más remedio que salir de esta situación de insolvencia y descrédito si quería que retornasen las inversiones extranjeras para superar su postración económica. Obregón convirtió, por ello, el arreglo de la deuda en su prioridad.

En efecto, los mercados internacionales premiaron el convenio De la Huerta-Lamont entre Estados Unidos y México de 1922 (véanse gráficas 5 y 11), el acuerdo con los banqueros franceses, así como el reconocimiento de las reparaciones a los empresarios extranjeros que sufrieron daños durante la revolución, ya en 1923. Quedó pendiente, no obstante, el compromiso de pago de la deuda emitida en 1913 por Huerta, la del estado de San Luis Potosí y una parte de las obligaciones que puso en circulación la empresa pública Mexican Packing Co. (CFB, 1922). La quiebra del Banque Française du Mexique en 1922 fue el último episodio de la crisis financiera. De hecho, a lo largo de ese año reabrieron los grandes bancos (Canadian, Montreal y Londres), sujetos ahora a un encaje de 30\% (CFB, 1922, p. 256).

México retomó la senda del crecimiento gracias a la labor del nuevo secretario de Hacienda desde 1923, Juan Alberto Pani, y su plan de reforma económica. Pero, sobre todo, las exportaciones de petróleo impulsaron la recuperación. La producción del país pasó de representar 3.7\% del total mundial en 1910 a cerca de un tercio en 1923 (CFB, 1922, p. 259). 
Sin embargo, la restructuración económica no tuvo la menor influencia en la actividad de la Bolsa, que estaba sumida en la postración más absoluta (véanse gráficas 9 y 10). Pani no mostró mayor preocupación por su declive. Su única reforma, menor, consistió en la creación de un fondo de garantías de los corredores. Incluso, dada la reducción del déficit público y el consiguiente descenso del tipo de interés, las emisiones de deuda resultaron menos atractivas para los inversores (véase gráfica 3).

Mientras crecía el volumen de las exportaciones y el PIB per cápita, la Bolsa languidecía (véanse gráficas 2, 7 y 9). Ello obedeció a la moderación de los precios de la plata y del petróleo, sectores a los que estaban vinculadas las empresas de mayor volumen de contratación. Pero sobre todo, este distanciamiento de las cotizaciones bursátiles de las transformaciones tangibles que, en el plano real, estaba viviendo el país fue el resultado de la desconfianza que entre los agentes económicos suscitó el manejo de la deuda externa y el temor, a la vista de los precedentes, de que desencadenase una nueva crisis bursátil (véanse gráficas 7 y 8 ).

Las suspicacias estaban plenamente justificadas. El 1 de enero de 1924, México suspendió el pago de la deuda externa, lo que provocó una caída del volumen de intercambio de valores y de los precios en la Bolsa (véanse gráficas 1,2 y 10).

El nuevo presidente del país desde diciembre de 1924, Plutarco Elías Calles, conocido como el Jefe Máximo, confió otra vez a Pani la tarea de renegociar la deuda. En octubre de 1925 llegó a un acuerdo de arreglo con el denominado International Committe of Bankers, que agrupaba al conjunto de acreedores de México. El tratado contemplaba el reinicio del pago de intereses en 1928 y la privatización total de los ferrocarriles. Casi simultáneamente, Pani concedió el monopolio de la emisión de billete al Banco de México, lo que puso fin al caos monetario de la revolución $(\mathrm{Ca}-$ vazos, 1976; СFв, 1925, 1926; Oñate, 2000).

$\mathrm{El}$ arreglo tuvo efectos muy positivos en las finanzas mexicanas. Después de tres lustros ininterrumpidos de caídas, por fin subió la cotización de los títulos de renta variable en la Bolsa de México. Otro tanto sucedió en el exterior (véanse gráficas 1, 2 y 4). De hecho, en 1926 en las Bolsas de París, Nueva York, Ginebra y Londres estaba al alcance de los inversores la compra de más de medio centenar de títulos mexicanos (LagunillaIñarritu, 1973, pp. 271-272).

El sosiego duró poco. Obligado por los gastos en que incurrió para derrotar al movimiento cristero, en 1927 el gobierno mexicano cesó -una vez más- el pago de la deuda externa. La cotización de valores mexicanos se hundió, dentro y fuera del país (véanse gráficas 1, 2 y 4). En 1927 el país entró en recesión. El asesinato de Obregón, presidente electo en 1928, enrareció todavía más el ambiente. En pocos meses los problemas 
políticos habían dilapidado el legado de Pani fuera del gobierno. México se precipitaba, una vez más, al abismo.

\section{LA CRISIS DE 1929 Y SUS CONSECUENCIAS}

A pesar de que el país parecía haber tocado fondo en materia financiera, sufrió la misma crisis de 1929 que el resto de América Latina, a tenor de los todavía escasos datos disponibles (véase gráfica 12, y Cárdenas, 1987).

Como sucedió en 1920, en México a la caída de las exportaciones se unió la depreciación de la plata (véanse gráficas 9 y 11). Por otra parte, el cambio de signo en la coyuntura coincidió fatalmente en el tiempo con la quiebra y liquidación paulatina de los bancos de los estados, privados del negocio de la emisión. Pero, sobre todo, una nueva y más acentuada crisis de deuda abrió la espita.

El estallido de la sangrienta rebelión escobarista contra el ya constituido como Partido Nacional Revolucionario (el actual PRI), controlado por Plutarco Elías Calles, alimentó la inquietud de los capitalistas foráneos. Tras años de conflictos y de gobiernos efímeros que aplicaron políticas erráticas, los inversores extranjeros clamaban por un interlocutor ecuánime con quien dialogar. El liberal Ortiz Rubio, nuevo presidente de la república desde febrero de 1930, parecía ser ese hombre. A él se refirieron los tenedores británicos como un "civilitian president to guide México in the right direction" (CFB, 1930, pp. 257).

No obstante, tras sufrir un atentado que obligó al retiro momentáneo del presidente de la vida pública, Elías Calles siguió en la sombra rigiendo los destinos económicos del país, con escaso acierto, desde su condición de presidente del Banco de México. Atendiendo a sus órdenes, el gobierno contrajo en julio de 1930 un préstamo al 4\% con el National City Bank por 15000000 de dólares, ampliables en ocho más. Con estos recursos pretendía, mediante operaciones de mercado abierto, sostener la cotización del peso y de los metales preciosos (CFB, 1930, p. 266). Fue inútil. El préstamo no hizo otra cosa que elevar a niveles insoportables la deuda externa y acrecentar la desconfianza en Europa y Estados Unidos (véanse gráficas 4 y 8).

Conminado por el International Committe of Bankers, en enero de 1931 el gobierno de México acordó una conversión de su deuda exterior (incluida la ferroviaria), ahora unificada en títulos a 5\% amortizable en 45 años. A pesar de las ventajosas condiciones (no devengaba intereses hasta 1932 y sólo debían abonarse en plata, muy depreciada, durante dos años), no recibió la preceptiva sanción del parlamento (CFB, 1930, p. 266).

Tras esta resolución, las cotizaciones bursátiles sufrieron una caída aún más intensa que la del otoño de 1929, seguida de una masiva retirada de 

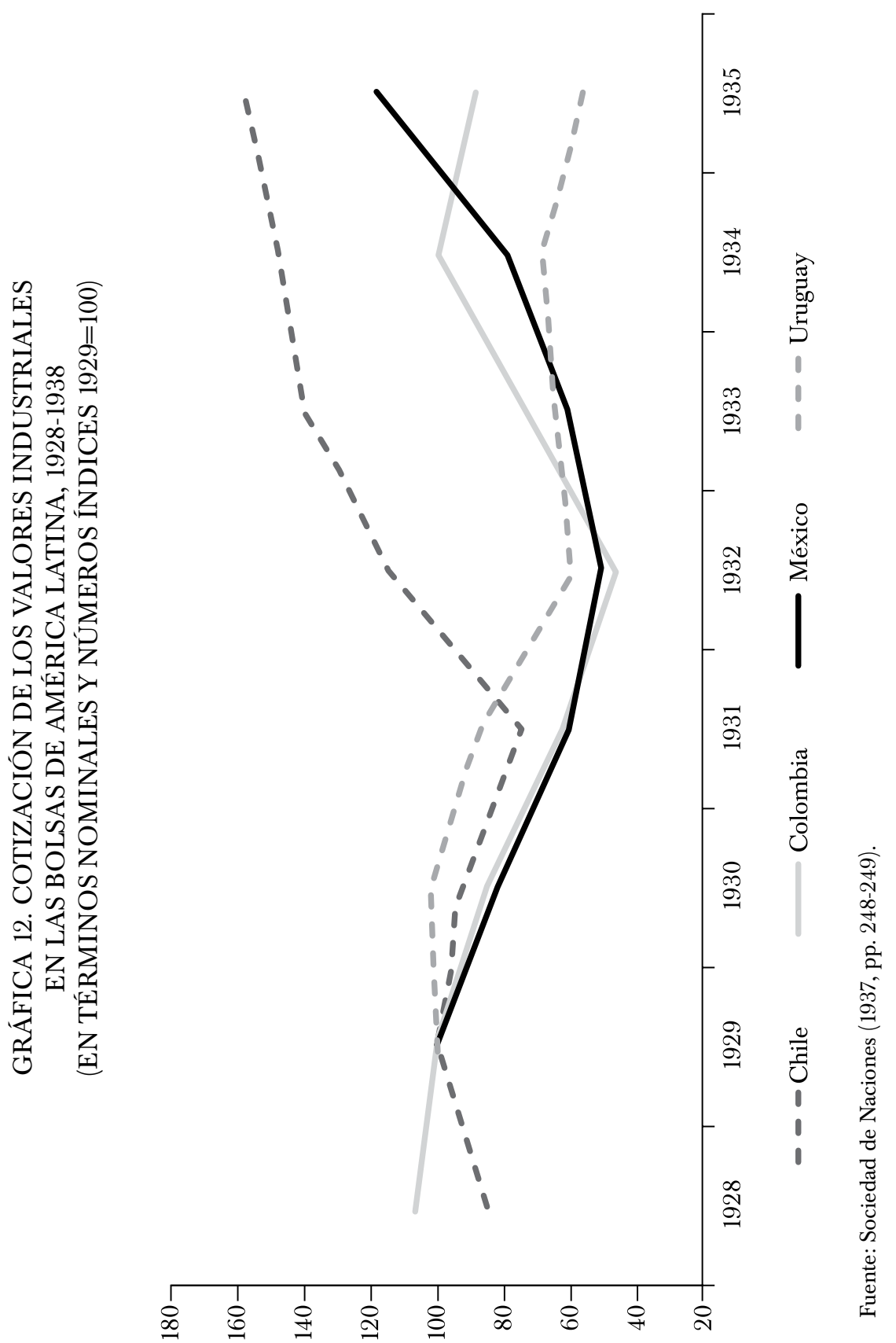
depósitos (Lagunilla-Iñarritu, 1981, p. 169) (véanse gráficas 1 y 2). En 1931 se produjo una cascada de quiebras de bancos, iniciada con el de Sonora (Banco de México, 1931). México abandonó el patrón oro. La producción petrolera mexicana retrocedió a los niveles de 1915, es decir, menguó en más de 600\% (Vega, 1999).

En tales circunstancias, el gobierno decretó en marzo el cierre de la Bolsa durante tres meses, cierre que, al cabo, se prolongó durante todo el año (Lagunilla-Iñarritu, 1981, p. 16). México, un país devastado por más de dos decenios de conflictos bélicos y revueltas, estaba sumido en la depresión económica más profunda desde su nacimiento como nación. Los deudores extranjeros, conscientes de esta situación, fueron generosos. En diciembre de 1931 concedieron una moratoria en el pago de la deuda hasta 1934 .

El escenario cambió por completo con la llegada a la presidencia de Abelardo L. Rodríguez, en septiembre de 1932, y el fin de ese periodo de hegemonía de Elías Calles conocido como el Maximato, de cuya senda, en política económica, se apartó. A las reformas laborales, educativas y agrarias se unieron las no menos trascendentales en el mercado de capitales, y especialmente en la Bolsa.

Rodríguez confió esta tarea a Pani, de nuevo responsable de la Secretaría de Hacienda y Crédito Público. Obligado por la presión política, denunció el acuerdo de 1931. Sus cláusulas -argumentó- eran abusivas (Lagunilla-Iñarritu, 1981, p. 165). Sabedor de la trascendencia de este nuevo repudio, promovió en la Conferencia Latinoamericana de Montevideo la declaración de una moratoria conjunta durante seis años por parte de todos los países acreedores. No tuvo éxito. Cierto es que Brasil, Chile, Ecuador y Bolivia suspendieron el pago de la deuda. Pero otros, como Argentina, Uruguay, Colombia e incluso los países centroamericanos, siguieron honrando la suya, aunque con gran dificultad. México se aisló financieramente y acrecentó su desprestigio, lo que disuadió la inversión extranjera.

En un segundo término, Pani reconstituyó la Bolsa, ahora compuesta por sólo 60 socios. Su actividad quedó reglada en la Ley de Reordenación Bancaria de 1932 (Caso, 1971, p. 63). Pani le confirió entonces la misión de ofrecer deuda pública interior en forma prioritaria, de ahí su apreciación (véase gráfica 3). Así pues, ratificó la consideración de la Bolsa como un instrumento al servicio de las necesidades de financiación del sector público que diseñó Carranza. Al final Pani culminó sus reformas con la atribución de mayores poderes al Banco de México.

Pani supo conciliar este mayor control de la actividad económica y su prioridad por garantizar la estabilidad financiera con los intereses de las grandes firmas, con lo que se sentaron las bases del corporativismo genui- 
namente mexicano. Con el propósito de facilitar la financiación empresarial y evitar un conflicto de intereses, Pani redujo el tipo de interés de 12 a 8\%. Asimismo, aumentó la oferta monetaria para contener la deflación, devaluó el peso e incrementó el gasto público (Banco de México, 1932). Al cabo, estas medidas de estímulo de la demanda agregada no sirvieron, en lo que a la Bolsa atañe, de gran cosa (véanse gráficas 10 y 12).

La institución continuó por completo al margen de la trayectoria económica (véase gráfica 9). Su labor como intermediario financiero era marginal, como venía sucediendo desde el inicio de la revolución. La diferencia ahora radicaba en que esa marginalidad no obedecía exclusivamente a la voluntad expresa del gobierno.

La comparación con lo sucedido en Argentina también permite imputar esta debilidad al atraso económico de México (véase cuadro 2). Ahora bien, precisamente la consideración de las cifras de uno y otro país revela la responsabilidad del sector público. La escasa implantación de la Bolsa en México no es congruente con el tamaño relativo de su economía. De hecho, la diferencia en el desarrollo bancario entre ambos países era sustancialmente menor. La acción del Estado explica esta paradoja. Desde la revolución, los gobiernos, uno tras otro, pusieron más trabas al intercambio de acciones, trabas que alcanzaron su cénit con la reforma de Pani. El resultado fue el empequeñecimiento deliberado de una institución en la que no confiaban, justo cuando en otras economías del continente sucedía lo contrario.

\section{CONCLUSiOnes}

El precio de las materias primas y productos primarios pautó la evolución de las cotizaciones en la Bolsa de la Ciudad de México, como en las del resto de las economías de América Latina. En este caso, la subordinación a las exportaciones de plata y petróleo fue absoluta, como en la de Buenos Aires a la de trigo o en La Habana a la de azúcar. Pero las similitudes con otras Bolsas vecinas no van mucho más allá. De hecho, la Bolsa en México constituye un caso absolutamente excepcional entre las de otras grandes economías exportadoras de América Latina. Su trayectoria, en la que no hubo un solo instante de sosiego, la pautó el ideario en materia económica de los responsables del diseño de la política económica del periodo, de quienes quedó mayor huella: Limantour, liberal, y Pani, un converso al keynesianismo y entusiasta de la intervención.

El comienzo de la revolución supuso un antes y un después en la historia de la Bolsa mexicana. El desarrollo experimentado en los tres últimos lustros del siglo XIX no tuvo parangón en América Latina, por lo repentino 


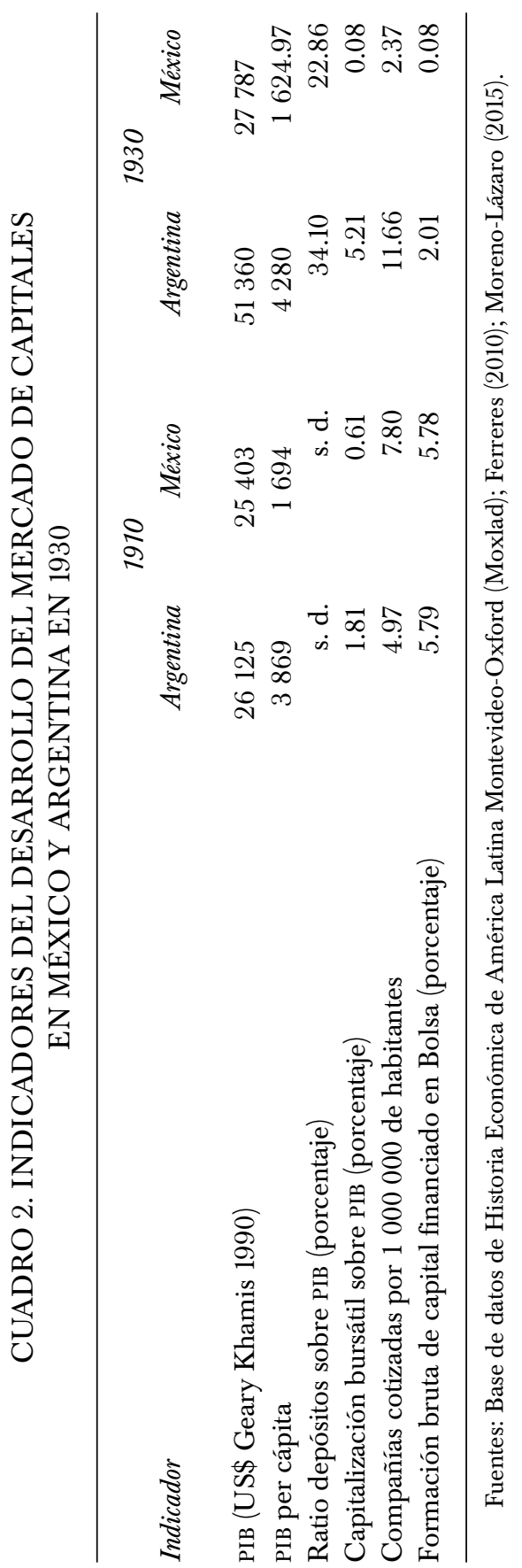


y por su magnitud. Se ganaba dinero fácil en la compraventa de acciones, a pesar del declive del precio de los minerales y de las bases tan frágiles en que se sustentaba el mercado de capitales vertebrado en 1897. Los ahorradores mexicanos creyeron ingenuamente encontrar en la titularidad de las empresas mineras una garantía de sus inversiones. Pero no todo fue mera falacia financiera. Las empresas mineras y manufactureras encontraron en la Bolsa un instrumento de obtención de recursos muy útil, habida cuenta del escaso desarrollo del crédito bancario.

Sin embargo la revolución frustró esos logros. La inestabilidad política provocó una parálisis total de sus actividades al espantar literalmente a los inversores extranjeros. El conflicto afectó mucho más a las finanzas que a la actividad productiva del país, debido a la incertidumbre que generó y a las dudas sobre el ejercicio de la libertad de empresa.

Es cierto que ese empequeñecimiento de la Bolsa y del propio mercado de capitales fue común en la trayectoria en el largo plazo de las economías capitalistas avanzadas desde 1913 (Rajan y Zingales, 1998); pero en México es mucho más perceptible.

La propia debilidad del sistema financiero y la deficiente definición de los derechos de propiedad causaron el declive de la actividad bursátil. No se trata sólo de que los bancos en 1929 arrastrasen en sus problemas a la Bolsa. En un país, incluso haciendo abstracción del caos monetario vivido entre 1913 y 1917, cuando el uso del billete se generalizó tan tardíamente, con un sistema bancario atomizado y poco integrado (el tipo de interés en el crédito agrario llegó a 60\% en plena deflación de la década de 1930), construir un mercado de valores con una mínima fortaleza resultaba poco menos que imposible.

Al tiempo, las dificultades de la Hacienda atenazaron a la Bolsa. Por un lado, los continuos repudios provocaron frecuentes crisis bursátiles. Las caídas repentinas en las cotizaciones, acompañadas de las quiebras bancarias por la implicación del crédito en la actividad de la Bolsa, vinieron precedidas de una crisis de deuda, el auténtico detonante. La insolvencia de la Hacienda originaba una expulsión de los valores mexicanos de las Bolsas extranjeras si no había acuerdo con los acreedores y una quita parcial, seguida de un canje con títulos emitidos a un interés y rentabilidades mayores. Las grandes empresas exportadoras recibían el castigo de los inversores, tras ser estigmatizadas, en el primero de los casos; en el segundo, se inclinaban por la renta fija, ahora mucho más atractiva.

Con todo, los apuros de la Hacienda no bastan por sí solos para explicar la debilidad de la institución. La mencionada Argentina la sufrió con tanta o mayor dureza y experimentó en este periodo un notable desarrollo de su mercado de acciones. El Estado, en México, fue culpable. Los gobiernos de la revolución, sobre todo desde que Carranza se hizo cargo de 
la presidencia del país, atribuyeron a la Bolsa consecuencias financieras perversas y la responsabilidad de un caos en el mercado de capitales del que ellos eran culpables. Por otra parte, consideraban que la fortaleza de la Bolsa tenía dos consecuencias perjudiciales para sus intereses: comprometía la colocación de bonos y democratizaba el acceso a la financiación por parte de las grandes compañías, sin necesidad de acudir al auxilio público. Es decir, la Bolsa podía debilitar no sólo económica, sino también políticamente el nuevo orden en construcción desde 1910.

La solución dada para solventar ambos problemas consistió en emplear a la Bolsa sólo para vender deuda al tiempo que ayudar en forma selectiva y discrecional a los empresarios mediante préstamos de la banca pública. Se sentaron así las bases de un orden financiero corporativista vigente hasta finales del siglo $\mathrm{XX}$, basado en el miedo al mercado. Cuando Cárdenas llegó a la presidencia en 1934 se encontró con parte del trabajo hecho. Sólo tenía que dar mayor solidez a este statu quo. Para entonces, el número de empresas que se financiaban en el exterior superaba con creces a las pocas que perseveraban en hacerlo en la Bolsa de México, que estaba sometida a los caprichos del Estado.

Su debilitamiento tuvo consecuencias fatales para el desarrollo económico de México en el primer tercio del siglo xx, un periodo de fuerte crecimiento de las economías más extravertidas de Iberoamérica. No es ninguna conjetura presumir que, sin esta subordinación, el sector industrial habría contado con un auxilio financiero vital para su robustecimiento. Sin duda alguna así aconteció antes de 1910, por más que la especulación desdibuje su contribución a la financiación de las grandes firmas mineras. Otro tanto sucedió desde que en 1975 comenzó a atenuarse el control estatal de una institución cuyo libre funcionamiento tanto inquietaba a los gobernantes.

Por tanto, cabe culpar al Estado de la endeblez de la Bolsa, por su obstinación en endeudarse y en anularla. Sin embargo, conviene tener presente también un factor determinante en el comportamiento de los inversores mexicanos. Todas las crisis bursátiles y repudios de la deuda relatados en estas páginas, así como las situaciones de incertidumbre, provocaron una masiva huida de capitales a Estados Unidos. La vecindad -muy nociva en aspectos financieros- con este país tuvo una importancia capital. De hecho, dada la seguridad y rentabilidad que aseguraba la Bolsa de Nueva York, resulta casi un milagro el empuje de la Bolsa de México en los años de la primera globalización. 
Anexos

CUADRO 1. ÍNDICE DE LAS COTIZACIONES DE LOS TÍTULOS DE RENTA VARIABLE EN LA BOLSA DE LA CIUDAD DE MÉXICO, 1884-1934 (EN NÚMEROS ÍNDICES BASE 1900)

\begin{tabular}{|c|c|c|}
\hline Año & Términos reales & Términos nominales \\
\hline 1888 & 25.6 & 21.4 \\
\hline 1889 & 32.7 & 28.9 \\
\hline 1890 & 44.1 & 36.8 \\
\hline 1891 & 136.2 & 106.5 \\
\hline 1892 & 207.3 & 178.3 \\
\hline 1893 & 174.9 & 157.4 \\
\hline 1894 & 389.4 & 354.4 \\
\hline 1895 & 344.3 & 302.4 \\
\hline 1896 & 128.2 & 112.9 \\
\hline 1897 & 200.4 & 180.6 \\
\hline 1898 & 119.3 & 107.4 \\
\hline 1899 & 149.8 & 139.9 \\
\hline 1900 & 100.0 & 100.0 \\
\hline 1901 & 58.7 & 75.4 \\
\hline 1902 & 70.9 & 91.2 \\
\hline 1903 & 81.4 & 104.6 \\
\hline 1904 & 93.1 & 106.4 \\
\hline 1905 & 86.0 & 110.6 \\
\hline 1906 & 113.4 & 145.8 \\
\hline 1907 & 94.9 & 122.0 \\
\hline 1908 & 81.7 & 105.0 \\
\hline 1909 & 98.6 & 140.9 \\
\hline 1910 & 56.1 & 96.2 \\
\hline 1911 & 52.0 & 75.9 \\
\hline 1912 & 51.8 & 77.4 \\
\hline 1913 & 44.6 & 68.3 \\
\hline 1914 & 37.8 & 64.1 \\
\hline 1915 & 30.0 & 184.9 \\
\hline 1916 & 0.8 & 193.7 \\
\hline 1917 & 19.2 & 41.0 \\
\hline 1918 & 29.7 & 64.9 \\
\hline 1919 & 28.7 & 79.6 \\
\hline 1920 & 14.1 & 46.1 \\
\hline 1921 & 9.4 & 25.6 \\
\hline
\end{tabular}


Año

1922

1923

1924

1925

1926

1927

1928

1929

1930

1931

1932

1933

1934
Términos reales

9.8

11.2

8.8

11.8

8.8

6.6

15.5

12.3

7.3

9.8

7.1

5.6

23.2
Términos nominales

22.3

27.1

20.1

28.6

21.5

15.2

35.5

28.1

16.6

19.6

13.2

13.0

45.6

Fuentes: El Economista Mexicano (1888-1915); Excélsior (1916-1934); Gómez-Galvarriato y Musacchio (2000); Lagunilla-Iñarritu (1973); Noriega y Rodríguez-Pérez (2011); Instituto Nacional de Estadística, Geografía e Informática (2009).

CUADRO 2. ÍNDICES SECTORIALES

DE LA BOLSA DE MÉXICO, 1888-1934

(EN NÚMEROS ÍNDICES BASE 1910 Y EN TÉRMINOS NOMINALES)

\begin{tabular}{lccc}
\hline Año & Minería & Banca & Industria \\
1888 & & & \\
1889 & - & 22.2 & - \\
1890 & - & 30.0 & - \\
1891 & 40.5 & 29.6 & - \\
1892 & 133.3 & 22.2 & - \\
1893 & 228.6 & 16.4 & - \\
1894 & 200.0 & 21.6 & - \\
1895 & 457.9 & 18.4 & - \\
1896 & 389.3 & 21.1 & - \\
1897 & 142.6 & 23.3 & 116.3 \\
1898 & 286.9 & 28.0 & 125.6 \\
1899 & 145.9 & 32.2 & 96.9 \\
1900 & 137.5 & 42.0 & 182.6 \\
1901 & 120.4 & 54.9 & 100.0 \\
& 94.4 & 65.6 & 64.9
\end{tabular}




\begin{tabular}{|c|c|c|c|}
\hline$A \tilde{n} o$ & Minería & Banca & Industria \\
\hline 1902 & 108.3 & 68.9 & 87.5 \\
\hline 1903 & 115.5 & 65.6 & 113.5 \\
\hline 1904 & 108.9 & 76.7 & 122.0 \\
\hline 1905 & 108.0 & 87.8 & 130.2 \\
\hline 1906 & 164.3 & 87.6 & 155.6 \\
\hline 1907 & 122.6 & 82.2 & 143.9 \\
\hline 1908 & 113.0 & 85.8 & 111.6 \\
\hline 1909 & 204.1 & 96.7 & 98.6 \\
\hline 1910 & 100.0 & 100.0 & 100.0 \\
\hline 1911 & 72.8 & 88.9 & 82.9 \\
\hline 1912 & 73.7 & 81.8 & 87.4 \\
\hline 1913 & 62.6 & 75.6 & 78.8 \\
\hline 1914 & 72.8 & 72.4 & 58.5 \\
\hline 1915 & 201.4 & 186.7 & 184.2 \\
\hline 1916 & 196.3 & 533.3 & 115.5 \\
\hline 1917 & 30.0 & 23.3 & 61.5 \\
\hline 1918 & 28.8 & 29.7 & 119.4 \\
\hline 1919 & 55.8 & 32.2 & 125.7 \\
\hline 1920 & 31.4 & 20.4 & 73.3 \\
\hline 1921 & 17.7 & 14.9 & 39.4 \\
\hline 1922 & 12.7 & 20.7 & 35.2 \\
\hline 1923 & 12.7 & - & 52.7 \\
\hline 1924 & 10.3 & - & 38.0 \\
\hline 1925 & 20.4 & 19.2 & 42.7 \\
\hline 1926 & 13.2 & 17.1 & 33.6 \\
\hline 1927 & 6.7 & 19.3 & 24.5 \\
\hline 1928 & 37.2 & 14.7 & 42.7 \\
\hline 1929 & 18.2 & 12.2 & 45.9 \\
\hline 1930 & 5.2 & 8.4 & 32.7 \\
\hline 1931 & 6.1 & 3.2 & 40.4 \\
\hline 1932 & 4.9 & 4.9 & 25.6 \\
\hline 1933 & 11.4 & 9.1 & 39.3 \\
\hline 1934 & 61.1 & 8.6 & 40.9 \\
\hline
\end{tabular}

Fuentes: El Economista Mexicano (1888-1915); Excélsior (1916-1934); Gómez-Galvarriato y Musacchio (2000); Lagunilla-Iñarritu (1973); Noriega y Rodríguez-Pérez (2011); Instituto Nacional de Estadística, Geografía e Informática (2009). 
134 Javier Moreno Lázaro

CUADRO 3. ÍNDICE DE LAS COTIZACIONES DE LOS TÍTULOS DE RENTA FIJA EN LA BOLSA DE LA CIUDAD DE MÉXICO 1888-1934

(EN NÚMEROS ÍNDICES BASE 1900)

\begin{tabular}{|c|c|c|}
\hline Año & Términos nominales & Términos reales \\
\hline 1888 & 63.0 & 75.3 \\
\hline 1889 & 68.9 & 77.8 \\
\hline 1890 & 63.8 & 76.4 \\
\hline 1891 & 53.8 & 68.7 \\
\hline 1892 & 62.2 & 72.3 \\
\hline 1893 & 62.2 & 69.0 \\
\hline 1894 & 63.0 & 69.2 \\
\hline 1895 & 88.5 & 100.8 \\
\hline 1896 & 95.2 & 108.2 \\
\hline 1897 & 102.3 & 113.5 \\
\hline 1898 & 99.2 & 110.2 \\
\hline 1899 & 112.0 & 119.9 \\
\hline 1900 & 100.0 & 100.0 \\
\hline 1901 & 112.5 & 87.5 \\
\hline 1902 & 126.9 & 98.7 \\
\hline 1903 & 128.9 & 100.2 \\
\hline 1904 & 128.7 & 112.6 \\
\hline 1905 & 131.8 & 102.5 \\
\hline 1906 & 131.0 & 101.9 \\
\hline 1907 & 126.1 & 98.1 \\
\hline 1908 & 128.6 & 100.0 \\
\hline 1909 & 133.4 & 93.4 \\
\hline 1910 & 134.2 & 78.2 \\
\hline 1911 & 128.3 & 87.8 \\
\hline 1912 & 123.0 & 82.3 \\
\hline 1913 & 135.2 & 88.4 \\
\hline 1914 & 134.6 & 79.4 \\
\hline 1915 & - & - \\
\hline 1916 & - & - \\
\hline 1917 & - & - \\
\hline 1918 & - & - \\
\hline 1919 & 130.0 & 46.9 \\
\hline 1920 & 57.8 & 17.7 \\
\hline 1921 & 43.3 & 16.0 \\
\hline 1922 & 43.9 & 19.2 \\
\hline 1923 & 47.7 & 19.6 \\
\hline
\end{tabular}


$A \tilde{n} o$

1924

1925

1926

1927

1928

1929

1930

1931

1932

1933

1934
Términos nominales

41.9

32.3

33.2

30.3

22.2

13.1

11.5

5.9

4.8

3.6

10.8
Términos reales

18.3

13.3

13.7

13.3

9.7

5.7

5.0

3.0

2.6

6.2

11.8

Fuentes: El Boletín Financiero y Minero (1916-1934); El Economista Mexicano (1888-1914); Lagunilla-Iñarritu (1973, pp. 245-271).

\section{CUADRO 4. COTIZACIONES MEDIA DE LOS VALORES MEXICANOS EN LAS BOLSAS DE LONDRES Y PARÍS, 1888-1933 (EN TÉRMINOS NOMINALES Y NÚMEROS ÍNDICES 1914=100)}

\begin{tabular}{lcc}
\hline Año & Deuda & Acciones \\
& & \\
1888 & - & 114.3 \\
1889 & 60.0 & 116.4 \\
1890 & 98.6 & 123.4 \\
1891 & 88.6 & 128.9 \\
1892 & 60.0 & 125.5 \\
1893 & 74.3 & 113.8 \\
1894 & 57.1 & 105.3 \\
1895 & 55.7 & 111.7 \\
1896 & 55.7 & 114.9 \\
1897 & 69.3 & 123.9 \\
1898 & 68.6 & 126.6 \\
1899 & 107.1 & 135.3 \\
1900 & 128.6 & 144.7 \\
1901 & 117.1 & 157.4 \\
1902 & 116.4 & 145.7 \\
1903 & 107.1 & 128.9 \\
1904 & 118.6 & 147.4 \\
1905 & 143.3 & 179.6
\end{tabular}




\begin{tabular}{|c|c|c|}
\hline$A \tilde{n} o$ & Deuda & Acciones \\
\hline 1906 & 143.5 & 229.3 \\
\hline 1907 & 143.4 & 268.8 \\
\hline 1908 & 136.2 & 264.8 \\
\hline 1909 & 139.2 & 221.2 \\
\hline 1910 & 145.5 & 265.5 \\
\hline 1911 & 141.8 & 227.9 \\
\hline 1912 & 143.2 & 228.6 \\
\hline 1913 & 129.9 & 209.0 \\
\hline 1914 & 107.5 & 114.5 \\
\hline 1915 & 100.0 & 100.0 \\
\hline 1916 & - & - \\
\hline 1917 & - & - \\
\hline 1918 & 93.4 & 117.7 \\
\hline 1919 & 105.2 & 145.0 \\
\hline 1920 & 112.3 & 345.8 \\
\hline 1921 & 138.3 & 405.8 \\
\hline 1922 & 100.9 & 221.0 \\
\hline 1923 & 121.3 & 220.8 \\
\hline 1924 & 128.2 & 253.0 \\
\hline 1925 & 98.7 & 245.0 \\
\hline 1926 & 119.0 & 444.4 \\
\hline 1927 & 173.9 & 473.8 \\
\hline 1928 & 166.4 & 312.5 \\
\hline 1929 & 125.5 & 221.8 \\
\hline 1930 & 84.6 & 154.8 \\
\hline 1931 & 58.9 & 129.4 \\
\hline 1932 & 5.3 & 59.2 \\
\hline 1933 & 6.0 & 46.4 \\
\hline 1934 & 5.9 & 48.5 \\
\hline
\end{tabular}

Fuentes: El Boletín Financiero y Minero (1916-1934); El Economista Mexicano (1888-1914); Lagunilla-Iñarritu (1973, pp. 245-271).

\section{LISTA DE REFERENCIAS}

Ángel, G. DEL (2002). Paradoxes of financial development. The construction of the Mexican banking system (Disertación doctoral). Universidad de Stanford, California, Estados Unidos.

BAnCo De MéXico (1931, 1932). Memoria anual. México: Autor. 
Bazant, J. (1968). Historia de la deuda exterior de México. México: Fondo de Cultura Económica.

CÁRdenas, E. (1987). La industrialización mexicana durante la gran depresión. México: El Colegio de México.

CÁrdenas, E. y Ángel, G. DEl (2011). Acciones y valores. La mejor inversión está en México. México: Accival.

CÁrdenas, E. y Manns, C. (enero-marzo, 1989). Inflación y estabilización monetaria en México durante la revolución. El Trimestre Económico, 56(1), 57-79.

CAso, J. (1971). El mercado de acciones en México. México: Centro de Estudios Monetarios Latinoamericano.

Cavazos, M. (1976). Cincuenta años de política monetaria. En E. Fernández (ed.), Cincuenta años de banca central. Ensayos conmemorativos, 1925-1975 (pp. 55-121). México: Fondo de Cultura Económica.

Corporation of Foreign Bondholders (1895-1930). Annual Report. Londres: Autor.

Costeloe, M. P. (2003). Bonds and bondholders. British investors and Mexico's foreign debt, 1824-1888. Londres: Praeger Publishers.

Dimson, E., Marsh, P. y Staunton, M. (2009). Triumph of the optimists: 101 years of global investment returns. Princeton: Princeton University Press.

Ferreres, O. (ed.) (2010). Dos siglos de economía argentina. Buenos Aires: Fundación Norte y Sur.

Gómez-Galvarriato, A. y Musacchio, A. (2000). Un nuevo índice de precios para México, 1886-1929. El Trimestre Económico, 67(1), 47-91.

HABER, S. (1989). Industry and underdevelopment: The industrialization of Mexico, 18901940. Stanford: Stanford University Press.

HABER, S. (1997). Financial markets and industrial development: A comparative study of governmental regulation, financial innovation and industrial structure in Brazil and Mexico, 1840-1930. En S. HABER (ed.), How Latin American fell behind. Essays on economic histories of Brazil and Mexico, 1800-1914 (pp. 146-177). Stanford: Stanford University Press.

Haber, S., Maurer, N. y Razo, A. (2003). The politics of property rights: Political instability, credible commitments and economic growth in Mexico, 1876-1929. Cambridge: Cambridge University Press.

Instituto Nacional de Estadística, Geografía E Informática (INEgi) (2009). Estadísticas históricas de México. México: Autor. Recuperado de http://www.inegi.org. $\mathrm{mx} / \mathrm{sistemas} / \mathrm{bie} /$

Kuntz, S. (2007). El comercio exterior mexicano en la era del capitalismo liberal. México: El Colegio de México.

Lagunilla-IÑarritu, A. (1973). La Bolsa en el mercado de valores de México y su ambiente empresarial. México: Bolsa de Valores de México.

Lagunilla-IÑarritu, A. (1981). Historia de la banca y moneda en México. México: Jus. 
Levy, J. (2012). Una cuestión de intereses: entre Benito, Maximiliano y Porfirio: una reforma liberal y la liberación de tasas de interés en Yucatán, 1850-1900. América Latina en la Historia Económica, 19(1), 157-177.

LOndon Bullion Market Association (2016). Silver Prices: 100 Year Historical Chart. Recuperado de http://www.macrotrends.net

Macedo, P. (1905). La evolución mercantil. Comunicaciones y obras públicas. La Hacienda Pública. Tres monografías que dan idea de una parte de la evolución económica de México. México: J. Villaseca y Sucesores.

MARICHAL, C. (1993). Foreign loans, banks and capital markets in Mexico, 1880-1910. En R. LieHR (ed.), La deuda pública en América Latina en perspectiva histórica (337374). Madrid: Vervuert/Iberoamericana.

MARICHAL, C. (1997). Obstacles to the development of capital markets in nineteenthcentury Mexico. En S. HABER (ed.), How Latin American fell behind. Essays on economic histories of Brazil and Mexico, 1800-1914 (pp. 118-145). Stanford: Stanford University Press.

Maurer, N. (2002). The power and the money. The Mexican financial system, 1876-1932. Stanford: Stanford University Press.

Méndez, J. (1996). La política económica durante el gobierno de Francisco I. Madero. México: Instituto Nacional de Estudios Históricos de la Revolución Mexicana.

Moreno-LÁZaro, J. (2015). The Stock Exchange, the State and economic development in Mexico, 1932-1976. Revista de Historia Económica/Journal of Iberian and Latin American Economic History, 33(2), 321-350.

Nacional Financiera (1977). Statistics of the Mexican economy. México: Autor.

Noriega, A. y Rodríguez-PÉrez, C. (octubre, 2011). Estacionariedad, cambios estructurales y desarrollo económico en México, 1895-2008. Working Paper núm. 2011-11, Banco de México.

OÑATe, A. (2000). La batalla por el Banco Central. Las negociaciones de México con los banqueros internacionales, 1920-1925. Historia Mexicana, 49(4), 631-672.

PAZ, F. (2006). La política económica de la revolución mexicana, 1911-1924. México: Universidad Nacional Autónoma de México.

Rajan, R. G. y Zingales, L. (junio, 1998). Financial dependence and growth. The American Economic Review, 88(3), 559-586.

Reina, P. (1958). La vigilancia del Estado sobre el mercado de valores. México: Comisión Nacional de Valores.

Reinhart, C. y Rogoff, K. S. (2008). This time is different: A panoramic view of eight centuries of financial crisis. National Bureau of Economic Research.

Riguzzi, P. (2001). Revolución y finanzas públicas: El caso del estado Estado de México, 1910-1928. Red Política y Cultura, 16, 203-234.

Romero, M. E. (2009). Patrón oro y estabilidad cambiaria en México, 1905-1910. América Latina en la Historia Económica, 16(2), 81-109.

SociedAd DE NACiOnes [League of Nations] (1937). Statistical year-book (1936-37). Ginebra: Economic Intelligence Service. 
SOLÍs, L. (1997). Evolución del sistema financiero mexicano. Hacia los umbrales del siglo XXI. Ciudad de México: Siglo XXI.

VEGA, Á. DE LA (1999). La evolución del componente petrolero en el desarrollo y la transición de México. México: Universidad Nacional Autónoma de México.

Williamson, S. (2016). Dailing closing value of the Dow Jones average, 1885 to the present. Recuperado de https://www.measuringworth.com/

ZebadúA, E. (1994). Banqueros y revolucionarios. La soberanía financiera de México, 19141929. México: Fondo de Cultura Económica/El Colegio de México.

\section{OTRAS FUENTES}

\section{Hemerografía}

El Boletín Financiero y Minero, Ciudad de México, México.

El Economista Mexicano, Ciudad de México, México.

Excélsior, Ciudad de México, México.

The New York Times, Nueva York, Estados Unidos.

\section{Archivos}

Base de datos de Historia Económica de América Latina Montevideo-Oxford (Moxlad).

Recuperado de http://moxlad-staging.herokuapp.com/home/es 